\title{
Kernos
}

Revue internationale et pluridisciplinaire de religion grecque antique

7| 1994

Varia

\section{L'inceste souhaité ou prohibé comme réalisant l'androgynie prêtée aux dieux (2e partie)}

\author{
Jacques-Numa Lambert
}

\section{OpenEdition \\ Journals}

\section{Édition électronique}

URL : http://journals.openedition.org/kernos/1111

DOI : 10.4000/kernos. 1111

ISSN : 2034-7871

Éditeur

Centre international d'étude de la religion grecque antique

Édition imprimée

Date de publication : 1 janvier 1994

ISSN : 0776-3824

Référence électronique

Jacques-Numa Lambert, «L'inceste souhaité ou prohibé comme réalisant l'androgynie prêtée aux dieux (2e partie) », Kernos [En ligne], 7 | 1994, mis en ligne le 20 avril 2011, consulté le 22 avril 2019. URL : http://journals.openedition.org/kernos/1111; DOI : 10.4000/kernos.1111 
Kernos, 7 (1994), p. 231-271.

\title{
LINCESTE SOUHAITÉ OU PROHIBÉ \\ COMME RÉALISANT L'ANDROGYNIE PRÊTÉE AUX DIEUX
}

\author{
(2e partie)*
}

\section{Chapitre III :}

\section{Les démons et Apollon}

Plutarque fait parler le savant lacédémonien Cléombrote qui raconte avoir rencontré un devin barbare inspiré ${ }^{1}$. Prophétisant une seule fois l'an, vivant dans la société des nymphes nomades et des démons, cet homme-là attribuait la divination aux démons et, s'agissant du Python de Delphes, à l'encontre de l'opinion courante que son meurtrier s'était enfui pour s'exiler pendant neuf ans à Tempé, il prétendait qu'après son acte, il «était passé dans un autre monde, où il avait séjourné pendant le cours de neuf grandes années au bout desquelles, devenu pur et vraiment Brillant (Phoibos) $)^{2}$, il était revenu pour entrer en possession de l'oracle, gardé pendant ce temps par Thémis".

Ainsi était postulée la possiblité pour un impur d'accéder à la sainteté, pour un démon de devenir un dieu. Cléombrote, louant les mages et Zoroastre ou bien Orphée le Thrace ou encore les Égyptiens ou les Phrygiens d'avoir imaginé la race des démons comme intermédiaires entre les dieux et les hommes, s'appuyait sur Homère et sur Hésiode pour montrer qu'on peut passer des dieux et des demi-dieux au rang de héros, de même que pour certains hommes à celui de héros et, de là, de bons démons (agathodémons). Il se trouve même que quelques âmes, sur un long espace de temps, se purifient par l'exercice de la vertu «au point de s'élever au-dessus des démons pour participer pleinement à

\footnotetext{
La première partie de l'article a été publiée dans Kernos, 6 (1993), p. 139-205.

1 De def. oracul.,421a-c (21). Toutes les traductions citées des Dialogues pythiques sont empruntées à R. Flacelière dans l'édition des Belles Lettres (t. vI des Euvres morales, 1974).

2 PluT., De E delph., 394a (21).
} 
l'essence divine", tandis que le mouvement inverse en rabaisse d'autres dans des corps mortels 3 .

On voit qu'une telle doctrine rendrait parfaitement compte de l'ascension d'Apollon à la plus haute divination à partir des talents qu'un démon meurtrier, mais par la suite purifié, hérite d'un autre démon (Python, ou plutôt démone, le dragon femelle Delphiné), sa victime.

Les beaux travaux de Georges Charachidzé nous apprennent aujourd'hui que, dans toute la montagne caucasienne et jusqu'à la plaine géorgienne, un personnage divin, un $X a t^{\prime} i$ (ange) nommé K'op'ala jouissait d'une immense renommée, liée en particulier à son célèbre sanctuaire xevsur de K'arat'i ${ }^{4}$. Il était, en effet, le patron d'un clan, les Likok'i qui vivent à Guro et l'adoraient comme guérisseur avant tout.

Dieu qui joue de la musique à la "porte du ciel» et prescrit impérativement la danse ${ }^{5}$, il s'incarne en la personne d'un pasteur, et ce sont des bergers, le couple apparemment ${ }^{6}$ incestueux d'un berger et d'une bergère, qui ont fondé son sanctuaire. "Protecteur des bergers» 7 , K'op'ala est lui-même propriétaire d'un immense troupeau de bovins, alimenté par les offrandes ${ }^{8}$. C'était jadis la base d'une richesse considérable ${ }^{9}$.

Le plus clair de son activité consiste cependant dans le massacre des démons nuisibles, les Devi, issus de la démonologie iranienne et correspondant aux daeva de l'Avesta, mais beaucoup moins puissants, moins cosmiques, moins mauvais : comme en Arménie, ils sont largement humanisés, mortels, et l'on pourrait dire moitié démons moitié hommes ${ }^{10}$.

De def. oracul., 414f-415c (10).

4 Georges Charachidzé, Le système religieux de la Géorgie païenne, Paris, 1968, p. 405 sq.

5 Ibid., p. 365-366.

6 Ibid. , p. 420-421, $427-428$ et 625 i.f.

7 Ibid., p. 367.

$8 \quad$ Ibid., p. $365,369-370$.

9 Ibid., p. 406.

10 Ibid., p. 342-343. 
Parallèlement, la nature de K'op'ala est double : à l'instar de la foudre, à laquelle il est étroitement lié ${ }^{11}$, il se révèle aussi bien force dangereuse que bienfaiteur de l'humanité ${ }^{12}$. S'il guérit, c'est qu'il constitue lui-même la maladie en se faisant présent dans le malade. Il est à la fois le poison et le remède. Comme par une incantation magique, on demande à K'op'ala: «Ce qui est maléfique, tourne-le en bénéfique !» 13 .

Créé par Dieu comme tueur de démons, il semble parfois être leur seigneur, en particulier il l'est de ceux qu'on appelle Kadzhi, qui lui obéissent ${ }^{14}$. Cela s'explique sans doute par son assimilation fondamentale à l'âme des morts ${ }^{15}$. Il a la faculté d'entrer en relation avec l'univers démoniaque et se borne souvent à négocier avec les démons, à qui il propose des échanges: ainsi, pour faire relâcher «une âme captive", il leur fait sacrifier par le clan un chevreau noir, égorgé «main à l'envers", détail qui souligne l'aspect magique qui se mêle à l'aspect religieux de sa personnalité ${ }^{16}$.

Ce rôle de libérateur des âmes captives de démons incombe à K'op'ala, qu'il s'agisse de l'âme d'un mort noyé, retenu par l'eau, écrasé sous une avalanche, étranglé (pendu dont l'âme ne peut plus sortir par le cou), ou de l'âme d'un vivant, notamment celle d'une femme "possédée» ${ }^{17}$. Un mythe exemplaire ${ }^{18}$ raconte les risques qu'encourait ainsi K'op'ala.

Les neuf frères Dev, dont la mère avait neuf têtes, se bâtissaient une maison (tour forteresse) au-dessous de lui. Il descend sur la terre, par ruse se fait embaucher pour les aider, soulevant seul des pierres énormes, puis lance sur eux sa massue et détruit tout ce qu'il y avait là. Cependant, l'un des Dev, éborgné, s'enfuit, que K'op'ala poursuit jusqu'à

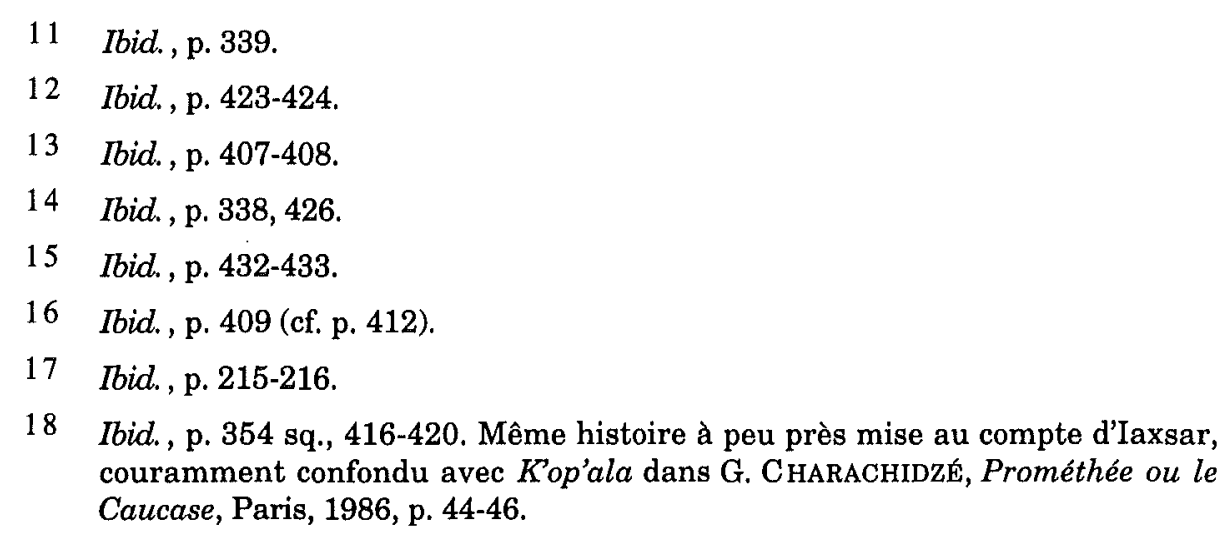


un lac où il plonge après lui, et il finit par le tuer. Mais, à ce moment-là, il s'aperçoit qu'il lui est impossible de remonter car ses ailes sont engluées de sang : le sang versé s'est retourné contre celui qui l'a versé. Le «libérateur de l'âme» est lui-même devenu prisonnier par une inversion de situation qui souligne son imperfection et la réciprocité de l'affrontement, comme dans les énigmes ou les ordalies primitives où la mort est l'inéluctable issue du défi pour l'un ou l'autre des deux parieurs.

Le $X a t^{\prime} i$ ne peut plus compter que sur ses "esclaves", les hommes du clan, qui reçoivent du kadag (prêtre) le conseil de découvrir une victime monstrueuse, un mouton à quatre cornes et quatre oreilles, pour l'immoler au bord du lac afin que l'âme du Xat'i puisse remonter du fond. Il leur faudra neuf ans pour découvrir la bête et délivrer leur maître.

Ainsi, au rebours de ce qui se passe dans le culte de K'op'ala, où il fournit aux démons une victime en échange de l'âme de son protégé humain captive au fond de l'eau, ce sont ses protégés humains qui offrent «au démon une victime en échange de l'âme de leur divin patron prisonnière dans l'abîme du lac. C'est ici le dieu qui tient la place de l'âme du noyé et qui ne peut être libéré que sur l'intervention des hommes» : jusque-là, K'op'ala prisonnier est assimilable à un mort ${ }^{19}$.

Les morts sont impurs, la pureté se confond avec la vie. K'op'ala a été purifié, comme ailleurs son alter ego Iaxsar le tueur de démons dont l'hymne célébrant la même aventure, au mileu du XXe siècle encore, correspond à un rituel de purification 20 .

La double conclusion du mythe le souligne: d'une part, K'op'ala revient à son essence divine en remontant du ciel et retrouvant les Xat'i ses congénères; d'autre part, il «demande à Dieu de tendre une corde ou un filin (parfois un fil, selon les variantes) entre la pierre où il secoue ses ailes humides et le sanctuaire de K'arat'i». Il renoue ainsi à la fois avec le ciel et avec le lieu terrestre de son culte, lui-même en relation continue avec le monde céleste par un fil mystique ${ }^{21}$.

C'est ainsi qu'après les neuf années d'expiation qu'Apollon, fuyant le lieu du meurtre de Python, était allé passer dans la vallée de Tempé, purifié, il était revenu à Delphes pour entrer en possession du vieil oracle des démons, gardé entretemps par Thémis, et qui était devenu le

\footnotetext{
19 ID., op. cit. (n. 4), p. 419.

20 ID., op. cit. (n. 18), p. 44-46.

21 ID., op. cit. (n. 4), p. 420.
} 
$\operatorname{sien}^{22}$. Le nom de K'op'ala ne résonne-t-il pas comme celui d'Apollon? Abelaur est l'une des appellations du mythique lac de sang, qui ne correspond à aucun lac connu, mais bien à Abalus, l'Avalon médiéval, l'«île aux pommes» ou île Fortunée, celle de la guérisseuse Morgane, que le roi Arthur ne quitta plus après y avoir été conduit pour panser les blessures de sa dernière bataille. Krappe supposait déjà qu'Apollon était le dieu d'Abalus ${ }^{23}$.

La pomme convient à l'île des Bienheureux comme un fruit d'immortalité. L'eau du lac Abelaur porte le nom qui désigne l'eau en langage «divin»: simur et qui se retrouve pour appeler celle où K'op'ala, "divinité chasseresse", change de nature et se métamorphose en cerf dès qu'il en approche ${ }^{24}$. Non seulement $K$ 'op'ala subit en effet l'irrésistible attirance de l'eau, et surtout de l'eau pure et glacée, mais aussi tout humain possédé par un Xat'i et destiné à devenir kadag ${ }^{25}$. On sait (Ginouvès) qu'Apollon était le patron des eaux froides, comme Héraclès celui des eaux chaudes, et que ce grand chasseur avait les biches pour fidèles compagnes 26 .

Cléombrote relevait que la race des démons se décèle en un pays par la grande place qu'occupent dans les cérémonies et les drames sacrés la mort et les manifestations de deuil ${ }^{27}$. Qui dit âme dit mort, la séparation du corps. La principale cérémonie funéraire des Xevsur, la course du Doghi, est destinée à procurer à certains défunts dans l'au-delà le «cheval de l'âme qui leur est indispensable», et elle a son pendant dans le k'op'aloba pshav, apparemment étrangère à K'op'ala, mais en étroite relation avec son culte ${ }^{28}$. Ainsi, la captivité prolongée de $K^{\prime} o p^{\prime} a l a$ au fond du lac représente la mort terrestre du Xat'i sous forme d'âme égarée $^{29}$.

22 Plut., Quest. gr., 12; De def. oracul., 21.

23 E.R. DoDDs, Les Grecs et l'irrationnel, tr. fr., Paris, 1965, p. 161, n. 36.

24 G. CHARACHIDZÉ, op. cit. (n. 4), p. 419. Cf. p. 360.

25 Ibid., p. 146-49.

26 L. SÉChAN, P. LÉVÊQUE, Les grandes divinités de la Grèce, Paris, 1966, p. 206, n. 77.

27 PLUT., De def. oracul, 415a i.f. (10).

28 G. ChARACHIDZÉ, op. cit. (n. 4), p. 375.

29 Ibid. , p. 429. 
Ce n'est pas une captivité, mais une servitude qu'Apollon a dû subir chez un "mortel", Admète, roi de Phères, comme berger de ses troupeaux, pour avoir tué de ses flèches vengeresses les Cyclopes, ouvriers de la foudre dont Zeus avait frappé son fils Asclépios tentant de ressusciter un mort ${ }^{30}$. Cet esclavage du dieu pendant un an n'était-il pas également une mort terrestre ? Comme le pensait Marie Delcourt, Admète, "l'Indomptable», est, à l'instar d'Adraste, «l'Inévitable», un des noms de la Mort, son pays, l'outre-tombe. "Quand Apollon allait chez Admète, cela signifiait qu'il mourait pour renaître ensuite après une année, disait-on anciennement, après une "Grande année" selon l'interprétation tardive» 31 .

Au surplus, l'Hymne à Apollon de Callimaque remplace pour son temps d'expiation Admète par les Hyperboréens. Or, l'Hyperborée, demandait Marie Delcourt ${ }^{32}$, n'est-elle pas «une terre d'utopie, le royaume bienheureux des morts ?"

Certes, concède-t-elle, il ne reste pas de trace d'une Hyperborée funéraire. L'étymologie du mot a toute chance de rendre simplement l'idée d'un pays situé au-delà du Vent $d u$ Nord (Borée) dans lequel on voyait le séjour d'Apollon, dieu dont Krappe a montré que les origines doivent être recherchées en Europe septentrionale ${ }^{33}$.

Apollon était "protecteur du blé» (Sitalkas) et «Métaponte, Myrina, Apollonie envoyaient périodiquement à Delphes les prémices de leurs récoltes ou un cadeau en or qui en représentait la valeur (offrande collective des Moissons d'or) "34. Ne répondent-ils pas aux «Orges d'or» - la récolte de l'orge constituait dans la Géorgie païenne une cérémonie religieuse ${ }^{35}$ - que le dieu céleste géorgien Morige, l'«ordonnateur", distribuait chaque année à l'occasion du nouvel an entre les Xat'i, c'està-dire entre les groupes humains que ces diverses divinités patronnaient? Elles "constituaient pour les «charnels» (les humains) un nantissement en échange de la récolte annuelle» 36 .

30 Marie DelcourT, L'oracle de Delphes, Paris, 1955, p. 161.

31 Ibid., p. 156-157, 160.

32 Ibid., p. 158-160.

33 E.R. DodDS, op. cit. (n. 23), p. 141 et n. 36 (p. 161).

34 M. DelCourT, op. cit. (n. 30), p. 160.

35 G. CHARACHIDZÉ, op. cit. (n. 4), p. 248 sq., 708.

36 Ibid., p. 281. 
Tant s'en faut que l'origine directement nordique du dieu exclue qu'il soit aussi passé, par l'autre côté du Pont Euxin, en Asie, où, de toute façon, si, au lieu du pays des Hyperboréens, c'est en Lycie, selon une autre tradition, qu'il se rendait en quittant Delphes chaque hiver ${ }^{37}$, c'est encore chez Homère la terre des morts qui reçoit Sarpédon endormi ${ }^{38}$.

Sans aller si loin, l'opinion courante veut qu'Apollon, après le meurtre de Python, ait gagné la vallée thessalienne de Tempé ${ }^{39}$ afin de se purifier du sang répandu du serpent "par l'exercice de la vertu, au point de s'élever au-dessus des démons pour participer pleinement à l'essence divine" 40 .

Tous les neuf ans se célébraient donc successivement à Delphes trois fêtes, dont la première, le Septérion, prétendait représenter le combat victorieux d'Apollon, puis sa fuite et ses purifications à Tempé ${ }^{41}$. D'après ce texte de Plutarque, la fête consistait essentiellement à répéter l'acte primordial qui avait été accompli par «lirruption silencieuse» d'une troupe jusqu'à la cabane ou, plutôt, la demeure d'un roi ou, plutôt, d'un tyran maître des lieux ${ }^{42}$. Elle arrive par le passage dit depuis la Dolonie ou passage du loup, par référence au Troyen Dolon ${ }^{43}$, ce qui signifie plus encore que marcher à pas de loup : il s'agissait d'un groupe opérant à l'image d'une bande de loups.

Faut-il penser à quelque ethnie qui ait entendu s'assimiler à la société des loups et en prendre le nom selon une conception religieuse archaïque dont le monde indo-européen fournit maints exemples (les Daces, certains Scythes, les Dauniens, les Lycaones d'Arcadie...) ${ }^{44}$ ou bien, plutôt, à l'une de ces Männerbünde, confréries de jeunes guerriers ou de magiciens qui revêtaient rituellement une peau de loup et, devenus des «hommes-loups", troquaient leur comportement humain en celui de l'animal, rôdant en quête d'agressions ou de rapines - le rapt et le vol

37 L. SÉCHAN, P. LÉVÊQUE, op. cit. (n. 26), p. 202.

38 M. DelcourT, op. cit. (n. 30), p. 160.

39 PluT., Quest. gr, 12.

40 Plut., De def. oracul., 415b (10).

41 Ibid. , 418b (15).

42 Ibid. , 418a (15). Cf. R. FLACELIÈRE, op. cit. (n. 1), p. 188, n. 6, citant Pausanias et Strabon.

43 Iliade, $\mathrm{X}, 314 \mathrm{sq}$.

44 M. Eliade, De Zalmoxis à Gengis-Khan, ch. Ier, p. 13 sq. 
constituaient plus des prouesses que des délits - comme ce carnassier, dans un univers magico-religieux «dominé par la solidarité mystique entre le chasseur et le gibier", dont la situation est toujours interchangeable?

En Afrique, en Inde, en Amérique, le mimétisme entraînait ces «loups à deux pattes» jusqu'à dévorer la chair humaine en de vrais repas de cannibales ${ }^{45}$. En Europe, bien au-delà d'un simple terrorisme, il y avait souvent invasion de territoire et brutale fondation d'un monde nouveau ${ }^{46}$. Rome a été fondée par les Fils de la Louve. Le mythe généalogique des Gengiskhanides proclame que leur ancêtre était un Loup gris, qui descendit du ciel et s'unit avec une biche... ${ }^{47}$

Il y avait justement dans la montagne du Parnasse un héros fameux par sa ruse et ses larcins, qui en faisaient le plus grand des voleurs. Attaquant le palais d'Amyntor, il en avait notamment enlevé un casque de type mycénien en cuir de bœuf doté de dents de sanglier qui devait devenir le casque d'Ulysse, petit-fils de cet homme par sa mère ${ }^{48}$. Il s'appelait Autolycos, nom qui "ne peut signifier autre chose que loupgarou" ${ }^{49}$. L'Apollon du Parnasse, l'Apollon de Delphes porte précisément l'épiclèse de Loup, $\Lambda v \kappa \omega ́ p \varepsilon 10 \varsigma^{50}$, du nom d'un des sommets du

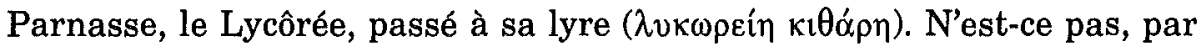
allusion à la ruse, au dol du loup - mais tout dolus n'est pas dolus malus ${ }^{51}$ - qu'Apollon est dit Loxias, «oblique, louche, équivoque», un nom, suppose Marie Delcourt ${ }^{52}$, qui dut être d'abord celui d'un démon ?

Le nom de Lykôrée vient précisément des loups qui, lors du déluge de Deucalion, servirent de guides par leurs hurlements vers les sommets du Parnasse à une partie des habitants de la toute première cité qu'avait fondée Parnasse, celui qui inventa de prendre les augures d'après le vol

Ibid. , p. 18-19, 26.

46 Ibid., p. 29.

47 Ibid., p. 30.

48 Il., X, 267; Od., XIX, 394 sq.

49 H. JEANMAIRE, Couroi et Courètes, Lille, 1938, p. 400.

50 Callimaque, Hymne à Apollon, 19. L'asile du Capitole, fondé par Romulus, était placé sous la protection du dieu Lucoris, identifié au Lykoreus de Delphes, M. Eliade, op. cit. (n. 44), p. 16. Sur Apollon-Loup en général, cf. SÉCHAN-LÉVÊQUE, op. cit. (n. 26), p. 219, n. 72.

51 ERNOUT-MEILLET, Dictionnaire étymologique de la langue latine, s.v.

52 M. DelCourT, op. cit. (n. 30), p. 163. 
des oiseaux : reconstruite, la cité s'en appela Lycôrée avant de prendre le nom de Pytho aussi bien que celui de Delphes ${ }^{53}$.

Quand donc, à la manière des loups, Apollon survient par la Dolonie pour la délivrer du serpent, selon un thème constant qui va d'Horus ou de Marduk, jusqu'à nos saints évangélisateurs, et ouvrir par là une ère nouvelle ${ }^{54}$, il n'est, selon la description du Septérion par Cléombrote, qu'un coros amphithalès amené là par des Æolades, deux énigmes qui n'en forment qu'une.

L'inceste est, en effet, à la base de la définition des Eolades, la spécificité d'Éole, le Maître des Vents, et de sa famille chez Homère ${ }^{55}$ observons en passant que le vent accompagne en règle les exploits de $K^{\prime}{ }^{\prime} p^{\prime} a l a^{56}$. Quant à l'amphithalès, nous savons ${ }^{57}$ qu'il est un enfant ou un jeune garçon riche - ce qui correspond tout à fait au portrait d'Apollon chez Callimaque ${ }^{58}$-, gâté par son père et sa mère toujours en vie et qu'on fait assister à un mariage pour en favoriser la fécondité; l'usage en est quasi universel et nous avons montré qu'il est dans son principe le propre frère de la fiancée intervenant entre les deux époux comme rappel et symbole du premier éveil des sens entre frère et sceur ${ }^{59}$, considérés pour cette raison comme des époux archétypiques du mariage en dépit de la prohibition de leur union incestueuse ${ }^{60}$.

La tendre nostalgie attachée à cet idéal perdu s'attarde justement dans le monde encore paien en 1917 des Pshav et des Xevsur, adorateurs de K'op'ala : c'est une coutume enracinée chez eux que, dans le village et souvent dans le même clan, un jeune homme et une jeune fille s'étant épris l'un de l'autre se déclarent "frère et sœur par serment" et se considèrent dès lors comme "frère-époux" et "sœur-époux". Il vont s'aimer en des rencontres nocturnes dans la tolérance générale, à la condition rigoureuse de ne pas engendrer, ce qui est réservé au mariage qu'ils contracteront un jour, mais nécessairement avec un autre

\footnotetext{
53 Pausanias, $\mathrm{X}, 6,1-5$.

54 Cf. MATH., III, 7.

55 Cf. Kernos, 6 (1993), p. 180.

56 G. ChaRADIDZÉ, op. cit. (n. 4), p. 349.

57 Cf. Kernos, 6 (1993), p. 180

58 Hymne à Apollon, 32 sq.

59 Cf. Kernos, 6 (1993), p. 194 sq.

60 Ibid., p. 166 sq.
} 
partenaire. Cette coutume s'appelle c'ac'loba chez les Pshav et, chez les Xevsur, qui, bien que la désapprouvant, la pratiquent aussi, sc'orproba. Les Pshav, pour leur part, vont jusqu'à l'exiger comme une «activité sacrée", et même imposent les relations dans l'enceinte des sanctuaires lors de leurs fêtes religieuses 61 , tel le Doghi ${ }^{62}$.

Certes les c'ac'al ne sont pas réellement frère et sœur, l'union adelphique est prohibée, mais il est naturel de penser que cette pratique "para-incestueuse» se rattache à une époque archaïque où cette prohibition n'existait pas encore et où toutes les formes d'inceste étaient au contraire louées sous l'influence du mazdéisme iranien, tout comme l'inceste paraît avoir été admis par les Grecs tolérant l'existence des Aolades.

L'amphithalès amené à la lumière des torches fait supposer, dans la cérémonie commémorative du Septérion, la célébration d'un mariage dans la demeure de Python-tyran et sans doute la table que renversaient les Eolades était-elle la table du banquet de noces. Ne demandons pas de quelles noces il s'agissait, mais, lorsque K'op'ala rejoignait les Dev soi-disant pour les aider à bâtir leur forteresse, eux aussi «avaient une noce, les eaux en étaient agitées ${ }^{63}$ ": il y a donc là un élément essentiel car toutes les variantes du mythe correspondant d'Amirani, le Prométhée caucasien, dont nous allons parler, le mentionnent également: "Les Dev avaient un banquet de mariage..." 64 .

Cet autre mythe, que, parfois, annonce la fin du mythe du lac de sang, ne se rappoche pas seulement par là de la cérémonie répétitive du Septérion, mais plus encore par le rôle destructeur qu'y joue le feu. Il s'agit de la célèbre expédition menée contre le peuple démoniaque des Kadzhi par Saint Georges de X'axmat'i, le maître de cet autre sanctuaire xevsur ${ }^{65}$. K'op'ala n'en est plus le héros principal, mais, échappé de son lac, encore tout ruisselant, il rencontre Saint Georges pour lui dire «Là où tu iras, emmène-moi !» et il va l'accompagner dans cette nouvelle aventure $^{66}$.

61 Cf. Kernos, 6 (1993), p. 160 sq.

62 G. ChARACHIDZÉ, op. cit. (n. 4), p. 366-367, 372, 402-403.

63 Ibid., p. 418.

64 G. CHARACHIDZE, op. cit. (n. 18), p. 45.

65 ID., op. cit. (n. 4), p. 172.

66 Ibid., p. 354, 360-361. 
En fait, le nom de Saint Georges est appliqué à K'op'ala, comme, d'ailleurs, à d'autres $X a t^{\prime} i^{67}$, en sorte qu'on peut parfois les considérer comme «identiques» ${ }^{68}$. Du moins, pour la poursuite d'un parallèle entre Apollon et les Xat'i caucasiens, Saint Georges apparaît tout à fait complémentaire de K'op'ala. Il y a sans doute quelque raison pour qu'une église paléochrétienne de Saint Georges ait laissé sa trace dans un pavement de mosaïque du IVe siècle découvert près de ce qui est devenu le Musée de Delphes ${ }^{69}$.

Dès l'abord, nous découvrons que Giorgi, l'«ange voyageur", est dit "semblable au vent" 70 et en même temps "semblable au loup": "Qu'as-

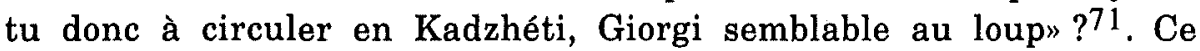
caractère errant et étranger l'assimile à cet animal, considéré luimême, par exemple en Svanétie, comme une personne, et même une personne bienfaisante: «selon les croyances svanes, les loups détiennent des pouvoirs magiques, qu'ils utilisent au bénéfice de l'humanité, aidant et protégeant les hommes de tout leur être». Aussi est-il interdit de les tuer en principe ${ }^{72}$, pas plus qu'on ne tue un frère de clan. Il n'est pas douteux que cette exception faite pour les loups, unique dans le monde des animaux sauvages, ne tienne à ce qu'ils forment entre eux une société de type humain ${ }^{73}$.

Le fait est d'autant plus remarquable que Giorgi est le patron des bergers, la divinité des alpages ${ }^{74}$, et donc appelé à combattre les loups pour défendre le bétail. Mais le respect bien connu du chasseur pour sa victime est ici poussé à sa limite : non seulement le loup tué est enterré en procession solennelle, mais pleuré comme un membre de la famille, et il se produit une véritable identification entre la victime et le chasseur. Aussi Giorgi est-il "Maître des Loups", et l'on n'a pas de peine à retrouver en lui la figure même d'Apollon, «Maître des fauves», lions

67 Ibid., p. 444-445.

68 Ibid., p. 337-338.

69 E. Goffinet, L'église Saint Georges à Delphes, in BCH (1962), p. 242 sq.

70 G. CHARACHIDZE, op. cit. (n. 4), p. 524.

71 Ibid., p. 517, 520, 524.

72 Ibid., p. 481.

73 Ibid., p. 482, 484.

74 Ibid., p. 479. 
et surtout loups, en même temps que protecteur des troupeaux ${ }^{75}$. Il en va, d'ailleurs, autant pour K'op'ala vis-à-vis des démons Kadzhi : il les tue, il les massacre, et cependant il est leur seigneur ${ }^{76}$, il règne sur eux comme sur beaucoup d'autres démons, et les Kadzhi lui obéissent ${ }^{77}$.

Donc saint Georges de Xaxmat'i flanqué du chef de guerre K'op'ala, s'en va, à la tête de l'armée des anges (Xat'i), détruire la ville démoniaque des $\mathrm{Kadzhi}^{78}$, qui sont des forgerons mythiques ${ }^{79}$ et magiciens. Il s'est fait accompagner par un homme (= l'âme de cet homme).

Au début, «il ne parvient pas à pénétrer dans la ville, une terrible flamme s'en dégage... Le forgeron des Kadzhi forgeait un plat. Saint Georges ensorcela le plat... la forge tout entière se mit à fulgurer et la bâtisse sauta au ciel». La puissance de Saint Georges est de nature magique. Être éminemment prédateur ${ }^{80}$, il emporte alors tout ce qui ne brûle pas, les femmes et le bétail - y compris une vache à une corne -, mais aussi au premier chef l'enclume et le marteau ${ }^{81}$. De retour à son torrent, il y allume une grande flamme.

Mais un événement extraordinaire se produit. Il y avait là, dans le village de Xaxmat'i, deux jeunes femmes dans une chambre, dont l'une avait une fille, l'autre un garçon. Cette dernière, sortant sur le pas de la porte, comme le jour se levait, s'écria devant ce bétail innombrable arrivé de Kadzhéti : "Avaj ! Qu'est-ce que cela ?» La mère de la fille, selon les versions ${ }^{82}$, ou bien lui cria, de la chambre où elle était restée : "Cela, c'est la puissance de Saint Georges de Xaxmat'i" - à moins que l'exclamation ne soit à mettre dans la bouche de la mère du garçon - ou simplement garda le silence, et ce silence eut sa récompense : sa fille fut instantanément changée en garçon, ce qui était une bénédiction car, dans le strict agnatisme des clans Xevsur, le sien s'éteignait avec une fille. En revanche, la mère du garçon, qui avait parlé, vit en punition son fils transformé par Giorgi en fille.

75 SÉCHAN-LÉVÊQUE, op. cit. (n. 26), p. 206.

76 G. ChaRACHIDZÉ, op. cit. (n. 4), p. 338.

77 Ibid. , p. 426.

78 Ibid., p. 447, 516 sq.

79 Ibid., p. 530, 536.

80 Ibid., p. 447.

81 Ibid., p. 531.

82 Ibid., p. $518 \S 6,522 \S 4$ et 5 . 
Deux surprises doivent ainsi trouver leur explication. Premièrement, qu'il soit possible de changer aussi facilement de sexe évoque et même suppose le caractère androgyne des humains, c'est-à-dire que chacun d'eux est en permanence doté des deux sexes, mais dont l'un est prépondérant, la balance penchant toujours soit vers le masculin soit vers le féminin. On retrouve dans l'anecdote quelque chose qui rappelle la coutume grecque si souvent signalée, notamment à Argos, de l'échange de leurs vêtements par les fiancés au moment du mariage.

Plus étrange est le fait qu'une si grande mutation soit liée à une cause apparemment aussi modeste que le silence ou les paroles intempestives des intéressés. Or cette particularité doit être d'une extrême importance, car on en rencontre l'équivalent un peu partout à travers l'espace et le temps. En substance, le bruit révèle quelque chose de mauvais par opposition au maintien du silence.

Il est probable que cela remonte aux conditions qui ont toujours été celles de la chasse : la prudence qui y est inhérente et exige le silence comme principale précaution aura été magiquement institutionalisée. Par contraste avec la légèreté de cris spontanément poussés et la stérilité de vaines gesticulations, le sage silence traduit la prise en considération de la grave portée de l'évènement : il doit être accueilli ou abordé avec un sang-froid qui commande toute action ou réaction. D'abord s'impose la réflexion, l'expérience en fait une attitude universelle.

Les mythes de l'Amérique tropicale, et, comme mythe de référence, tel mythe, au Brésil, des Indiens Bororo avaient couduit Cl. LéviStrauss à déceler de façon générale l'interférence du bruit dans certaines anomalies d'ordre social ou cosmique ${ }^{83}$.

Pour ce qui est des premières, l'ethnologue les rapprochait de l'usage bien connu en Europe du charivari sanctionnant des unions jugées répréhensibles, sinon même contre nature : remariage des veufs, maris battus par leurs femmes, mariage entre conjoints d'âge trop inégal ou violant les degrés de parenté prohibés, etc. Ce sont, d'ailleurs, remarquait-il, ces circonstances en elles-mêmes, tel le cocuage, qui sont visées plus que les personnes puisque le charivari s'adresse aussi bien, selon les cas, à la victime supposée $e^{84}$.

83 Le cru et le cuit, Paris, 1964, p. 333.

84 Ibid., p. 292-293. 
Mais si nos sociétés semblent retenir presque exclusivement pour ces vacarmes ${ }^{85}$ des circonstances sociologiques, dans les sociétés sans écriture considérées, ils sont pratiquement réservés à des conjonctures de nature cosmologique telles en particulier les éclipses, saluées dans le monde entier par des explosions de bruit dont l'Europe elle-même garde le souvenir non seulement à travers Tite-Live ou Tacite, mais d'hier encore, où l'on croyait qu'elles étaient dues à quelque loup dévorant la lune ou le soleil ${ }^{86}$. Il faut dire en contrepartie que l'Amérique précolombienne y attachait aussi des effets sociaux, menaçant surtout les femmes enceintes, dont on pensait par exemple que l'enfant à naître serait monstrueux si elles avaient eu l'imprudence de sortir pendant une éclipse ${ }^{87}$.

Dans le même ordre d'idées, c'est à un phénomène de société, l'inceste, que le mythe bororo ${ }^{88}$ rattache l'origine de la tempête et de l'orage :

«Dans des temps très anciens», les femmes étant allées en forêt pour cueillir les palmes dont on fait les étuis péniens (bá) remis aux adolescents lors de l'initiation et leur ouvrant le droit au mariage ${ }^{89}$, un jeune garçon suivit sa mère en cachette, la surprit et la viola. Le père s'en aperçoit et ne songe plus qu'à se venger : il envoie son fils accomplir diverses missions dont celui-ci ne devrait pas revenir, mais se tire sans dommage grâce à l'aide magique de sa grand-mère, par exemple rapporter les hochets de danse qui se trouvent au "nid" des âmes, i.e. leur séjour aquatique ${ }^{90}$. Pour son salut, il a pu également compter sur des oiseaux et lui-même se tranforme en quatre oiseaux avant de reparaître sous son aspect humain en présence de sa grandmère. "Cette nuit-là, il y eut une violente tempête, accompagnée d'un orage, et tous les feux du village furent noyés sauf celui de la grandmère». C'est lui désormais qui cherche à se venger de son père. À l'occasion d'une chasse collective qu'il a suggérée, il repère l'affût de son père, arme alors son front de bois travaillés en forme d'andouillers,

85 Ibid., p. 306-307.

86 Ibid. , p. 293, 334-336.

87 Ibid. , p. 335.

88 Mythe numéroté M1 et décrit par LÉVI-S TRAUSS, op. cit. (n. 83), p. 43 sq. et 292. Dans M2, il s'agit d'un inceste adelphique, ibid. , p. 57.

Ibid. , p. 52-53.

90 Ibid, , p. 65. 
"se change en cerf et charge son père avec une telle impétuosité qu'il l'embroche. Toujours galopant, il se dirige vers un lac où il précipite sa victime". Les piranha font le reste. Impossible de ne pas être frappé du parallélisme de certains de ces détails avec la métamorphose de $K^{\prime} o p^{\prime} a l a$ en cerf cornu dès qu'il rencontre l'eau ${ }^{91}$ et son plongeon dans un lac mythique.

Tout un contexte commun surgit alors : K'op'ala est un genie de l'orage lié à la foudre, à l'ouragan, à la tempête ("Le vent était là et hurlait" ${ }^{92}$ ), tout comme, dans une variante du chant bororo, le héros se venge de son père en lui envoyant "le vent, le froid et la pluie»93.

Les oiseaux bororo, notamment celui en lequel le fils se change pour laisser tomber sur l'épaule du père une fiente qui germe en un gros $\operatorname{arbre}^{94}$, rappellent que l'oiseau est la forme concrète de $K^{\prime} o p^{\prime} a l a^{95}$, comme de tous les Xat'i : il vient prendre possession de son esclave humain sous l'aspect d'un oiseau ${ }^{96}$, se donnant pour demeure un arbre ("corps de platane») ${ }^{97}$ dont la cime est attachée au ciel par un câble ou une chaîne d'or qui lui permet d'aller et venir entre ciel et terre et qui a valu à Georgi l'épithète d'«Ange du chêne»" ${ }^{98}$.

Il ne manque même pas au mythe bororo l'allusion faite à l'odeur suffocante de pourriture (des lézards tués) qui fait s'évanouir le héros ${ }^{99}$, la même pourriture grouillante de vers qu'est devenu le corps abandonné du mortel xevsur dont l'âme avait accompagné Saint Georges et les anges dans leur expédition contre les Kadzhi ${ }^{100}$, la même encore qui a donné son nom à Python (de $\pi \dot{v} \theta \omega$, «faire pourrir»).

\footnotetext{
91 G. ChARACHIDZÉ, op. cit. (n. 4), p. 354 sq., 431.

92 Ibid., p. 348-349, 353 et passim.

93 C. LÉvi-STRAuss, op. cit. (n. 83), p. 45.

94 Ibid., p. 57, 66.

95 G. Charachidze, op. cit. (n. 4), p. 427.

96 Ibid., p. 205 sq.

97 Ibid. , p. 220 sq.

98 Ibid., p. 659 sq.

99 C. Lévi-Strauss, op. cit. (n. 83), p. 44.

100 G. CHARACHIDZÉ, op. cit. (n. 4), p. 525.
} 
Dans les mythes bororo qu'il a étudiés, Lévi-Strauss relevait ${ }^{101}$ une opposition entre les deux moitiés exogames qui se répartissent les clans : l'une (les Tugaré) représente les créateurs et démiurges, "responsables de l'existence des choses», l'autre est constituée par les Cera qui «interviennent après coup comme les organisateurs et les gestionnaires d'une création dont les Tugaré furent les auteurs - le Morige caucasien se définit lui aussi comme "ordonnateur" (les génitrices et les mâles ?).

Lévi-Strauss fait observer que l'inceste du jeune Bororo n'est pas condamné en soi : c'est même le père qui fait figure de coupable et est finalement puni, coupable, puni pour avoir voulu se venger ${ }^{102}$. Il reste que l'inceste est la cause première d'un grave désordre et, s'il n'apparaît plus dans les mythes des autres tribus indiennes ${ }^{103}$, ne faut-il pas supposer une intention systématique de le masquer? Auquel cas, il pourrait bien en aller de même de l'arrière-plan des mythes caucasiens.

Sans en préjuger, revenons au sens profond que peut avoir l'opposition du silence et du bruit. S'il y a sur le sujet, entre l'Europe et l'Amérique, en dépit de leurs orientations différentes, une plus que probable communauté originelle du thème, nul, à notre connaissance, ne s'est encore avisé qu'elle transparaît également en Asie, et, ici, dès une haute époque historique, à travers le mythe mésopotamien le plus important depuis le XIe siècle avant J.-C., solennellement récité aux fêtes du Nouvel An, l'Enuma Elish («Lorsque en haut») ou Poème babylonien de la Création ${ }^{104}$.

Avant elle, lorsque n'existait encore ni le ciel ni la terre, l'Apsu primordial (l'eau douce et fertilisante) et la génitrice Tiamat (la mer salée et amère, source de toute vie) "mêlaient en un seul tout leurs eaux» ${ }^{105}$. Apsu et Tialat constituaient donc un seul être de nature

101 C. LÉvi-STRAuss, op. cit. (n. 83), p. 58, 63.

102 Ibid.

103 Ibid. , p. 292.

104 René LABAT, in Les religions $d u$ Proche-Orient, Paris, 1970, p. 36 sq.

105 1re Tablette, initio. Certaines des mythologies amérindiennes étudiées par Lévi-Strauss ne reconnaissent qu'une seule eau, la mer (Cru et cuit, p. 218). Dans le mythe des Bororo (ibid., p. 57), le héros, chaque fois qu'il s'arrête pour se reposer, provoque l'apparition des lacs et des rivières "car, à cette époque, l'eau n'existait pas encore sur la terre". 
androgyne. D'eux naquirent des dieux ${ }^{106}$ dont les premiers ont la même : Lahmou, Lahamou, Anshar Kishar qui signifient littéralement «totalité d'en-haut et totalité d'en-bas». Universellement un parallélisme a été établi entre rapports du Ciel et de la Terre et rapports sexuels ${ }^{107}$. On peut se demander si ce n'est pas contre l'inceste de Tiamat et d'Apsu que "se liguèrent (alors) les dieux, ces compagnons». "Ils troublèrent Tiamat, s'agitant en tous sens, ils perturbèrent le sein de Tiamat par le vacarme, ils jetèrent l'effroi aux demeures d'en haut et Apsu n'entendait pas diminuer leur clameur. Bien que Tiamat restât muette devant eux, pénibles lui étaient leurs actions...”108.

Apsu délibère avec son messager Moummou et Tiamat. Contre le sentiment exprès de Tiamat, il décide d'anéantir les perturbateurs, leur postérité, "pour que règne le silence et que nous, nous dormions" ${ }^{109}$. Les dieux, apprenant ce qui les menace, s'agitent d'abord, puis «gardent le silence et restent muets»110. Mais le plus intelligent d'entre eux, EaNoudimmoud, conçoit un plan pour prendre les devants, endormir Apsu, lui ôter sa couronne, s'en coiffer lui-même et le mettre à mort, enfin régner sur l'Apsu, Abîme des eaux douces. Désormais «Ea et Damkina», son épouse, bien distincte de lui, «en majesté demeurèrent» 111 .

Leur fils et successeur sera Marduk, créé par Ea et dont Damkina, sa mère, accoucha. Tout-puissant, omnivoyant, "Fils du Soleil, Soleil des dieux», "quand il remuait les lèvres, le Feu flamboyait» 112 . Cependant, sous le règne de Marduk, son grand-père Anu, fils d'Anshar et père d'Ea, enfante, crée de son sperme quatre vents de terreur et, par la tempête, perturbe gravement Tiamat, et les dieux, désormais sans repos, viennent se plaindre à elle, leur mère, coupable de n'avoir rien fait pour empêcher le meurtre d'Apsu et de ne s'en point venger. Condamnés à l'insomnie, ils la supplient de les délivrer pour qu'is puissent enfin dormir.

\footnotetext{
106 1re Tablette, 9 sq.

107 C. Lévi-S Trauss, op. cit. (n. 83), p. 295.

108 Enuma Elish, 1re Tablette, 21-27.

109 Ibid. p. 29-54.

110 Ibid. , p. 55-58.

111 Ibid. , p. 59-78

112 Ibid., p. 79-104.
} 
Que n'ont-ils pas demandé ! Tiamat les suit : «Faisons, dit-elle, des tempêtes !» Et d'enfanter d'horribles monstres, serpents géants, dragons furieux, pour grossir et renforcer le clan de jeunes dieux vengeurs qui se rassemble autour d'elle, à la tête duquel elle place Kingu, son filsépoux ${ }^{113}$.

La deuxième tablette montre Ea "gardant calmement le silence et sans mot dire», mais allant confier ses inquiétudes à son grand-père Anshar, dont les cris soulignent l'agitation jusqu'à ce qu'après une tentative avortée de conciliation menée par Anu, Marduk soit chargé par Ea et Anshar de vaincre Tiamat et Kingu, contre l'octroi de la souveraineté, ce que, dans les tablettes suivantes, il réussit parfaitement, et Ea lui-même, du sang de Kingu, crée l'humanité pour le service (la «libération») des dieux ${ }^{114}$. Tout se termine ainsi plutôt mal pour Tiamat, en qui il est difficile de ne pas voir la féminité.

Une autre conclusion à tirer est la conjonction du bruit fait par tout ou partie de la collectivité, phénomène sociologique, avec la tempête et le mauvais temps, phénomènes naturels : ils sont à l'unisson pour constituer un dérangement total dont, comme l'a mis en valeur Lévi-Strauss, l'inceste d'une part et l'éclipse de l'autre sont la plus claire expres$\operatorname{sion}^{115}$. Sans retenir les raisons qui lui permettent de les conjuguer, constatons simplement la généralité de la croyance qui assimile le soleil et la lune à un frère et une sœur : il n'y a point lieu dès lors de s'étonner du rapport de la cause de l'éclipse à l'inceste ${ }^{116}$, tel que l'établit par exemple un mythe eskimo, une autre façon de voir les choses étant le cannibalisme d'un astre qui en dévore un autre ${ }^{117}$. Le cannibalisme et l'inceste sont partout, d'ailleurs, en étroit rapport et ont été condamnés ensemble moins par des perscriptions juridiques que par l'horreur commune qu'ils ont fini par soulever. D'une façon ou de l'autre, la confusion des deux astres par une éclipse du soleil ou de la lune apparaît comme un terrifiant retour à l'Unité-bisexuée.

Revenant en Géorgie, on découvre dans le mythe d'Amirani, le Prométhée caucasien, un autre exemple d'opposition du silence au bruit qui fait progresser l'analyse.

113 Ibid., p. 105-162.

114 VIe Tablette, 32 sq.

115 C. LeVI-STRAUSS, op. cit. (n. 83), p. 293, 302 sq.

116 Ibid, , p. 318.

117 Ibid. , p. 302-305. 
Amirani, dont la force a anéanti tous les adversaires, n'a plus rien qui lui résiste et est suivi par l'ouragan ${ }^{118}$. Selon l'une des nombreuses variantes de sa geste ${ }^{119}$, il est, avec son père Zhadal, le maître du monde, mais le temps vient pour eux de se soumettre à un ordre nouveau.

Son orgueil, en effet, et son arrogance sont tels qu'il échoue au défi suprême assumé avec Dieu. Il s'avère incapable d'arracher une pierre, un arbre ou un pieu de fer planté en terre ${ }^{120}$ et, conséquence immédiate, c'est lui qui est immobilisé, enchaîné par Dieu ou par les Kadzhis pour l'éternité.

Trait remarquable, bien que sa victime eût été l'anéantissement $\mathrm{du}$ monde, seul Dieu la jugeait un mal, car les humains, pour leur part, déplorent sa captivité et même s'efforcent de le sauver ${ }^{121}$. Prométhée n'était-il pas l'ami des hommes et l'ennemi de Dieu ? Le Prométhée d'Eschyle n'est pas moins vrai que celui d'Hésiode ${ }^{122}$ et c'est là toute l'ambiguité des tricksters. Ainsi, dans les légendes circassiennes, les Tcherkesses font de leur pendant d'Amirani un fléau de l'humanité en même temps qu'un usurpateur de la souveraineté divine, mais l'autre grand rameau de l'ethnie, les Abkhazes, regrette l'âge d'or qu'on connut avec lui ${ }^{123}$.

Nous savons que les démons balancent de la même façon et, justement, ici, tout comme les Æolades-loups de Delphes en face de Python, ce sont les Kadzhi, les démons forgerons ${ }^{124}$, qui ont le beau rôle contre un Amirani qui non seulement bafoue Dieu, mais menace l'univers de destruction ${ }^{125}$. Le captif, cloué à la montagne, est toujours vivant et garde l'espoir de se libérer ${ }^{126}$. À ses côtés, son fidèle chien

118 G. Charachidzé, op. cit. (n. 18), p. 72.

119 Ibid., p. 73 sq.

120 Ibid., p. 94.

121 Ibid., p. 75-76.

122 Cf. Louis SÉCHAN, Le mythe de Prométhée, Paris, 1954, p. 27 sq.

123 G. CHARACHIDZÉ, op. cit. (n. 18), p. 76-87.

124 Une identification qui ne vaut pas seulement pour les Kadzhi (ibid., p. 46-72), mais de façon tout à fait générale (M. ELIADE, Forgerons et alchimistes, Paris, 1956, p. 84 et passim; Dictionnaire des symboles, s.v. Forgeron 2).

125 G. CHARACHIDZe, op. cit. (n. 18), p. 70-72.

126 Ibid. p. 102. 
Q'ursha lèche la chaîne moussue et rouillée qui l'immobilise, elle s'use, elle s'amincit au point de céder, mais à cet instant, tous les forgerons pénètrent tôt matin en silence dans leur forge, se mettent à forger muettement quelque chose, n'importe quoi, et la chaîne - par magie sympathique - se reforme aussitôt ${ }^{127}$.

Le forgeron, "s'il parle, la chose qu'il a faite n'a plus aucune valeur" 128 et son mutisme rituel, fatal au maintien d'Amirani dans les fers a pour contrepartie l'indiscret bavardage des femmes dont l'effet est décrit dans un autre type de tentative pour libérer Amirani.

Les récits ${ }^{129}$ font état de chasseurs égarés dans la montagne qui tombent par hasard sur le héros enchaîné et se prêtent volontiers à l'aider. Amirani demande en silence à l'inconnu de rapprocher de lui son épée qui gît non loin de là et avec laquelle il pourrait briser sa chaîne. Mais tous les efforts du chasseur pour la décrocher restent vains et Amirani entre dans une telle fureur que les montagnes s'écroulent et grondent comme le tonnerre.

Il y aurait cependant un moyen : que le chasseur rapporte de chez lui la "chaîne du foyer" fixée chez ces montagnards au toit de la pièce unique de la maison. Longue de quatre mètres et terminée par un «joug» à son extrémité supérieure, ce qui l'assimile à la courroie d'attache du bœuf à la charrue, elle est «une véritable échelle pour dieux et pour créatures célestes» par où «se maintient, se renouvelle la communication entre le ciel et la terre» et se mettent «en rapport l'univers des dieux et celui des hommes» ${ }^{130}$.

Avec cette rallonge, Amirani espère pouvoir haler son épée jusqu'à lui. Mais, dit-il au chasseur partant pour exécuter ses instructions, "si quelqu'un te voit, ne dis rien et ne te retourne pas». Le chasseur fait le nécessaire, mais, au moment où il repart de chez lui pour revenir à Amirani, «où donc emportes-tu la chaîne du foyer et la courroie de charrue ?» lui crie sa femme. Lui ne dit mot ni ne se retourne, mais elle insiste jusqu'à ce qu'excédé, il la roue de coups - cette attitude de la part d'une épouse xevsur lui vaudrait la mort ${ }^{131}$. Le temps cependant a passé

\footnotetext{
127 Ibid., p. 106-109.

128 Ibid., p. 109.

129 Ibid., p. 120 sq.

130 Ibid., p. 127 sq

131 Ibid., p. 123.
} 
et, quand le chasseur revient sur les lieux, il n'y a plus d'Amirani ni de crevasse où il se trouve.

Cela, Amirani l'avait bien prévu et, dans plusieurs versions, il a dit au chasseur : "Sache que ta femme se mettra après toi et te demandera où tu vas. Ne la regarde pas, malgré ses appels, sinon ma montagne se refermera". Voilà pourquoi "Amirani est l'ennemi des femmes. Il est aussi l'ennemi des forgerons" et, s'il "venait un jour à se libérer, il anéantirait tous les forgerons et toutes les femmes» 132 .

Ces dernières jouent parfaitement le rôle auquel Zeus, volé par l'orgueilleux Prométhée, a destiné Pandore, la Première Femme, envers et contre les hommes ${ }^{133}$. De fait, l'opposition bruit-silence en chevauche ou plutôt en découvre une autre, bien plus générale et importante, celle de l'homme et de la femme. Elle se manifeste avec éclat en Amérique chez les Indiens du groupe linguistique Gè, dont la mythologie, étudiée par Lévi-Strauss ${ }^{134}$, illustre à nouveau l'attitude contrastée vis-à-vis d'autrui, toute de sympathie masculine et de défiance féminine que vient de nous montrer le folklore caucasien.

Un jaguar porte secours au jeune homme perché sur un rocher abrupt où il est monté pour capturer les petits d'un couple d'aras et dont il ne peut descendre. Le jaguar l'y aide, puis l'amène chez lui, le fait manger de la viande grillée, alors qu'en ce temps-là les Indiens ne connaissaient pas le feu, et l'adopte comme son fils. Mais la femme du jaguar le déteste et lui cause mille misères, en sorte qu'il finit par la tuer avec les armes et sur le conseil même du jaguar. Revenu chez les siens, il les emmène voler le feu chez le jaguar qui en concevra une haine mortelle pour le genre humain. Sa femme n'avait peut-être pas eu tout à fait tort...

Autant en dire de la femme du chasseur dans le cas d'Amirani. Non seulement les actes d'Amirani avaient déjà presque dépeuplé la terre ${ }^{135}$, mais les aventures épiques du père (Artashès) de son homologue arménien, le roi Artawazd, plus proche des dieux que des hommes, s'achèvent par la destruction partielle du monde ${ }^{136}$. Nul doute

\footnotetext{
132 Ibid. , p. 122-123.

133 Hésiode, Travaux et Jours, 54 sq.

134 C. Léni-STrauss, op. cit. (n. 83), p. 74-81.

135 G. Charachidzé, op. cit. (n. 18), p. 100.

136 Ibid., p. 98-100.
} 
que «la conservation du monde tel que Dieu l'a créé a pour condition le maintien en captivité du supplicié»137.

Dieu n'a pas seulement enchaîné Amirani, mais il l'a entravé avec des glaciers et recouvert d'une immense montagne tandis que les montagnes s'ébranlaient et fermaient le chemin menant à lui ${ }^{138}$ : ce cataclysme qui se confond pratiquement avec son enchaînement ne faisait qu'annoncer «les bouleversements sismiques qui accompagnent les tentatives de libération auxquelles se livre le héros. Il y a concordance entre sa captivité et l'équilibre des forces telluriques : chaque modification apportée à son état de prisonnier... entraîne des remous spectaculaires mettant en cause l'ordre du monde dans sa structure géologique...»139.

Plus précisément, lorsqu'Amirani demande qu'on lui apporte la chaîne du foyer et la courroie d'attelage du bœuf à la charrue, ces deux instruments, estime Charachidzé ${ }^{140}$, "sont destinés à mettre en rapport le monde céleste et la terre des hommes. Ces substituts matériels représentent la contrepartie objectivement perceptible d'un dispositif symbolique beaucoup plus vaste : la conjonction du ciel et de la terre à quoi équivaudrait la libération d'Amirani. D'où l'on tire, par inférence immédiate, la proposition inverse : la disjonction du ciel et de la terre a pour corrélat le maintien du héros en captivité».

Tel est l'enseignement d'une imagerie qui "nous dévoile un pan de la doctrine même du mythe, l'un des théologèmes auquel il doit l'existence... Réduit à ses articulations essentielles, le crime d'Amirani consiste très exactement à supprimer l'écart souhaitable, normal, entre le ciel et la terre en provoquant leur conjonction abusive, un rapprochement intolérable entre l'espace de Dieu et celui des hommes. Ce sacrilège s'exprime de bien des manières, ne serait-ce qu'à travers l'impossible duel qu'Amirani ose offrir au maître de l'univers et qui entraîne aussitôt son châtiment..." Une grande partie de l'arsenal religieux, mythique, rituel de la civilisation caucasienne n'a pas d'autre fin que d'éviter à tout prix le sacrilège d'une telle conjonction.

137 Ibid., p. 101.

138 Ibid. , p. 67, 105, 106, 125.

139 Ibid, , p. 125.

140 Ibid., p. 129-130. 
Dieu y pare précisément en instaurant «une définitive disjonction entre Amirani et le monde supraterrestre, relégation qui se traduit par l'ensevelissement $d u$ héros..." Il "représente moins un châtiment qu'une mesure de protection. Il faut, pour la sauvegarde et la bonne marche de l'univers, qu'Amirani se trouve écarté de ce monde... Il est remarquable, ajoute notre auteur, que l'écart assurant l'équilibre des forces cosmiques ne puisse être restauré qu'en recourant à des agents humains, la femme d'un côté, le forgeron de l'autre".

Avec d'autres images, nous avons retrouvé le fol orgueil de l'entassement du Pélion sur l'Ossa, du combat des dieux contre les Géants, la Gigantomachie grecque ou le coup d'arrêt donné à la Tour de Babel. Créateur de l'ordre, Marduk avait dû pour ce faire, couper en deux le cadavre de Tiamat et en établir distinctement une moitié comme Ciel, l'autre comme Terre ${ }^{141}$.

La conjonction tant redoutée du ciel et de la terre, leur fusion en un seul être cosmique, on ne constestera pas que cela se traduise, en termes bio-sociologiques humains, par l'androgynie et l'inceste, et c'est contre eux que pourrait bien s'expliquer le rôle prêté aux femmes dans le maintien définitif d'Amirani aux fers.

Avec le christianisme, la vieille tradition se poursuit, le matin du jeudi saint, des forgerons muets forgeant un objet ou, au moins, battant leur enclume pour chasser les démons jusqu'à l'année suivante. De leur côté, «dans le courant de la journée, les femmes confectionnent du fil noir. Le soir venu, ces liens sont fixés autour des bras et des jambes des membres de la famille; ce sont les femmes qui s'acquittent de cette opération» ${ }^{142}$. «Ces entraves ont été filées pendant que, sous la masse de l'Elbrouz, se renforçaient et se reformaient les chaînes d'Amirani. Elles sont appliquées aux hommes le même jour, alors qu'Amirani se retrouve à nouveau enchaîné pour un an».

L'équivalence de ces fils avec les chaînes est attestée par le mythe lui-même ${ }^{143}$. La chaîne attache Amirani à un pilier de fer, mais aussi bien à un arbre comme ce hêtre que, sur le défi de Dieu, il a enroulé autour de lui ${ }^{144}$. L'image en évoque une autre, grecque, celle de l'Héra de Samos «adossée à un tronc de gattilier et entièrement liée par les plus

141 Enuma Elish, IVe Tablette, 136-138 et Ve, 62.

142 G. ChARAChIDZÉ, op. cit. (n. 18), p. 113-114.

143 Ibid., p. 119-120.

144 Ibid., p. 89. 
longs rameaux de l'arbre ramenés des deux côtés» 145. La déesse, coupable d'ávoir, avec l'aide de Borée, détourné Héraclès de son chemin marin de retour, avait aussi été liée par Zeus, qui accrocha à ses pieds deux enclumes et jeta autour de ses mains une chaîne d'or, infrangible; elle était restée là, suspendue en l'air, en pleins nuages ${ }^{146}$. Telle est également la position d'un chasseur mythique qui est le doublet d'Amirani, suspendu entre ciel et terre par la courroie constituée de la semelle de son mocassin ${ }^{147}$, et l'on sait comment Zeus prend Héphaistos par le pied et le lance vers la terre, où, tombé dans l'île de Lemnos ${ }^{148}$, il est adopté et instruit dans l'art du forgeron par la déesse Eurynomé, dont Pausanias évoque la statue liée par un fil d'or ${ }^{149}$.

Il existe d'autres preuves encore de ces parallélismes hellénocaucasiens. Le jeudi saint n'est que le point culminant d'une semaine que les Svanes appellent «la période des démons» et qui commence le lundi des Rameaux. Pendant cinq jours, il s'agit de chasser les démons, qui avec le temps, au cours des douze mois précédents, se sont progressivement infiltrés dans le village, dans les maisons et jusque dans le corps des habitants: "les dispositifs assurant normalement l'ordre du monde et l'organisation de ses composantes ne fonctionnent plus»150. Aussi les jours de cette semaine sont-ils "voués à l'abstention : silence, jeûne, immobilité, feux cachés ou éteints» - absence notamment en principe d'aliments cuits au foyer familial.

La gêne causée par ces interdits dans la grande famille a engendré la palliatif du «jeûneur» ( $m y t^{\prime} m e$ ) délégué. Un homme assume seul toutes les privations prescrites, restant pour cela "couché dans l'obscurité du matin au soir sans manger ni boire,... absolument silencieux et muet». Mais cette «immobilisation d'un homme, donc d'un travailleur, n'est pas à la portée de toutes les familles, surtout si elles sont peu nombreuses. Les Svanes ont prévu une pratique qui se substitue à la précédente et possède la même valeur symbolique : il suffit de lier et d'entraver une chaise de bois qui devient alors le myt'me, sans

145 Ménodote de Samos chez Athénée cité par Marie Delcourt, Héphaistos ou la légende du magicien, Paris, 1957, p. 100.

$146 I l ., \mathrm{XV}, 18-20$.

147 G. ChaRAChIDZÉ, op. cit. (n. 18), p. 129, 146 sq.

$148 I l, \mathrm{I}, 590 \mathrm{sq}$.

149 M. DelCOURT, op. cit. (n. 145), p. 43 sq.

150 G. Charachidzé, op. cit. (n. 18), p. 111-113. 
aucune intervention humaine» ${ }^{151}$. La chaise en effet, avec ses "pieds» et ses «bras", "propose la forme la plus humanisée de la condition mobilière en général» 152 . C'est l'équivalent d'Amirani captif.

Comment ne pas songer au parallèle du fameux trône d'Héra, forgé par son fils Héphaistos, qui l'a doté de liens invisibles en sorte que la déesse y est complètement immobilisée ? Hygin a raconté l'histoire ${ }^{153}$. Vulcain (= Héphaistos) avait, dit-il, fait pour Jupiter (= Zeus) et les autres dieux des soleae d'or, résistantes comme de l'acier - les soleae sont des sandales composées d'une semelle attachée sur le cou-de-pied par des cordons, d'où l'autre sens du mot: «entraves», comme celles de bois dans lesquelles on faisait passer les deux pieds des gens arrêtés ${ }^{154}$. Puis il enchaîne directement : «dès que Junon (= Héra) se fut assise, elle se trouva tout à coup suspendue en l'air». Autrement dit, Héphaistos avait fait pour Héra un siège, un trône figuré dans bon nombre de représentations de la scène de sa délivrance ultérieure ${ }^{155}$ où elle a les pieds sur un tabouret - Héphaistos place ainsi un «appui pour les pieds» ${ }^{156}$ - et où, naturellement, aucun lien n'apparaît puisqu'il s'agit de liens magiquement invisibles.

"On envoya, continue le fabuliste, chercher Vulcain (= Héphaistos) afin qu'il déliât sa mère après l'avoir enchaînée. Mais, furieux d'avoir été précipité du haut du ciel» - selon la version courante qui attribue le fait, non à Zeus, mais à Héra «honteuse de la claudication de l'enfant» (Libanios) -, «il répondit qu'il n'avait pas de mère. Alors Liber Pater (= Dionysos) l'amena vivre dans l'assemblée des dieux", en l'enivrant; pense-t-on généralement, «et il ne put se dérober à son devoir. Jupiter (= Zeus) lui promit de lui accorder ce qu'il demanderait. C'est alors que Neptune (= Poséidon), par hostilité envers Minerve (= Athéna), poussa Vulcain (= Héphaistos) à la demander en mariage. Vulcain (= Héphaistos) obtint ce qu'il demandait et entra dans la chambre nuptiale. Mais Minerve (= Athéna), conseillée par Jupiter (= Zeus), défendit sa

151 Ibid., p. 114-115, 118.

152 Ibid, p. 119, n. 1.

153 Fable 166. Cf. M. Delcourt, op. cit. (n. 145), p. 87-88.

154 ERnout-MeILlet, Dict. étymol., s.v. solum; A. RrCH, Dict. des Ant. rom. et gr., s.v. solea.

155 M. DelCOURT, op. cit. (n. 145), p. 90 sq.

156 Il., XIV, 239-240. 
virginité les armes à la main; dans la lutte, la semence du dieu tomba à terre..." d'où devait naître le petit Érichthonios.

Bien entendu, Hygin a ainsi soudé entre eux des épisodes mythologiques indépendants les uns des autres, rattachant en particulier contre toute évidence la tentative d'inceste dont Héphaistos s'était rendu coupable avec sa sœur Athéna au dégagement d'Héra de son trône. On n'en est pas moins impressionné par la nature de la "récompense" qui aurait été si facilement accordée au dieu pour s'être enfin résolu, après beaucoup d'hésitations, à libérer sa mère : un "mariage» qui a tous les aspects d'un inceste et d'un viol. Pourquoi, d'ailleurs, quels que soient ses motifs de rancune, Héphaistos avait-il enchaîné Héra ? Ne l'avaitelle pas mérité ? Et certes, le fils ne devait pas être très fier de sa naissance, due à un inceste adelphique, sinon à une conception sans père.

«Il faut souligner, remarquait Marie Delcourt ${ }^{157}$, dans tous les monuments qui traitent le retour d'Héphaistos, la richesse des indications sexuelles»: mulet, Silène accompagnateur ithyphalliques, thème des «grands yeux apotropaïques, lesquels sont le plus souvent associés à d'autres images qui servent également de remèdes contre la fascination» (fascinus = «charme» et aussi "phallus»).

$\mathrm{Au}$ centre des compositions à plusieurs personnages qui représentent la scène, on trouve Aphrodite accueillant Dionysos et Héphaistos sans qu'on puisse s'expliquer le rôle manifestement important qu'elle y jouait ${ }^{158}$, mais «comme si elle était l'enjeu du débat»159. Une autre rencontre d'Aphrodite et d'Héra était celle où, dans l'Iliade (XIV, 214 sq.), la première remet à la seconde un soutien-gorge brodé dans lequel "résident tous les charmes, tendresse, désir, entretien amoureux" afin de mieux séduire Zeus. Le plus lointain passé d'Héra nous est mal connu, mais laisse entendre qu'elle n'a pas toujours été la chaste et légitime épouse, déesse du couple conjugal qu'elle est devenue ${ }^{160}$. C'est la raison sans doute de l'oubli dans lequel tant les arts que la tradition littéraire ont pudiquement enfoui le thème de l'enchaînement d'Héra, comme on l'a relevé 161 .

157 M. DelCOURT, op. cit. (n. 145), p. 97.

158 Ibid., p. 91, 92.

159 Ibid., p. 78-79.

160 Cf. Kernos, 6 (1993), p. 187 sq.

161 M. DELCOURT, op. cit. (n. 145), p. 90, 93, 96. 
Mais ces chaînes, qu'Homère suggère déjà être des chaînes de métal, comme on pouvait s'y attendre étant donné la spécificité de forgeron qui est celle d'Héphaistos, et qu'Ovide imagine amenuisées à la lime ${ }^{162}$, paraissent bien avoir été des prises magiques et, par là, symboliques, comme il résulte de ce proverbe de la Souda «auquel on n'a peut-être pas apporté une attention suffisante", notait Marie Delcourt en l'exhumant très heureusement ${ }^{163}$ :

«Lien héphaistien se dit des choses inévitables. Ainsi un homme est ligoté par ses passions comme par des liens héphaistiens, infrangibles, indénouables et il y reste pris. Telles sont la folie amoureuse, l'ivrognerie, la cupidité».

Si la puissance des liens héphaistiens est ainsi reconnue comme éminemment psychique, il n'y a pas de raison qu'elle ne s'exerce en sens inverse et ils peuvent aussi bien symboliser une volonté contraire, capable de refréner les désirs et dompter les passions. Ses jeunes et folles ardeurs dominées, Héra allait rester l'irréprochable divinité du mariage, bien que, de son union consanguine, il n'y ait guère eu beaucoup de rejetons ${ }^{164}$.

C'est précisément Samos, où la fête des Tonea («des cordes») perpétuait la redécouverte de sa "statue", une très vieille image en forme de planche $(\beta \rho \varepsilon ́ \tau \alpha \varsigma)$, amenée là d'Argos soit par Admété qui avait été sa prêtresse dans la ville, selon l'opinion courante, soit par les Argonautes suivant Pausanias ${ }^{165}$, qui fut considéré jusqu'à la fin du monde antique comme un des hauts lieux de son mariage avec Zeus,

162 Mét., IV, 176 sq.

163 M. DELCOURT, op. cit. (n. 145), p. 63.

164 Cf. SÉCHAN-LÉVÊQUE, op. cit. (n. 26), p. 185 : «Épouse plus que mère..., les enfants qu'on lui prête sont deux étrangers, Arès et Héphaistos, introduits sans doute postérieurement dans sa légende, une Crétoise, Ilithyie, une abstraction, Hébé».

165 VII, 4, 4. Sur Argos et l'Héra argienne, cf. les références dans Kernos, 6 (1993), p. 192. C'est en Argolide, près d'Hermione, qu'on rencontre «les traditions les plus riches" sur le couple divin de Zeus et d'Héra (M. DELCOURT, op. cit. (n. 145), p. 104). On disait que Zeus s'était posé sous forme d'un coucou, donc lors du renouveau printanier, sur la hauteur où s'était assise Héra et où s'éleva par la suite le temple d'Héra matrimoniale (Teleia). Il y avait déclenché une tempête avant de la posséder. Ces détails rappellent les épiphanies des Xat'i caucasiens. 
prototype des unions humaines ${ }^{166}$. Tous les rites des Tonea indiquent une cérémonie nuptiale après un bain où elle retrouvait sa virginité dans le fleuve Imbrasos, nommé pour cela Parthénios ${ }^{167}$. Il paraît significatif que l'île où l'on plaçait préférentiellement le hieros gamos de régularisation ait été celle où les rites conservaient le souvenir d'une Héra Tonia, seule déesse avec, à Sparte, l'Artémis Orthia à avoir été liée (Lygodesma).

Aussi bien le mariage d'Héra est-il, dans l'Iliade, «coloré de détails héphaistiens» que Marie Delcourt s'est plu à colliger ${ }^{168}$. Ainsi, il est piquant de relever la contrepartie de son enchaînement, puis de sa délivrance par Héphaistos dans l'enchaînement de Zeus qu'elle demande à Sommeil (Hypnos), dieu lieur, qui, dédaigneux d'un siège ouvré par le forgeron qu'elle lui offre, consent finalement contre la promesse d'obtenir la main de Pasithéa, l'une des Grâces ${ }^{169}$.

Hypnos est frère de Thanatos, le Trépas, et c'est à juste titre que Marie Delcourt a reconnu dans Héra enchaînée «une valeur à la fois funéraire et nuptiale» 170 : il est bien vrai que «le conte du siège enchanté, dont on ne peut plus se relever..., apparaît toujours dans un contexte funéraire»171. L'iconographie nous la montre assise, "funérairement empaquetée» 172 . C'est un thème bien général que celui de l'assimilation du mariage à la mort, suffisamment illustré en Grèce dans le rapt de Coré par Hadès. Mais il ne peut s'agir ici, comme dans les mythes caucasiens, que d'une mort suivie de résurrection: "la femme qu'Héphaistos entrave, puis délie est un être qui meurt et qui renaît à la vie parce que le magicien a exercé sur elle ses sortilèges» ${ }^{173}$. $\mathrm{Au}$ demeurant, Héra est une Immortelle et c'est du mariage qu'elle est restée indissociable ${ }^{174}$.

166 M. DELCOURT, op. cit. (n. 145), p. 103.

167 Ibid., p. 101-103.

168 Ibid., p. 105-106.

$169 I l .$, XIV, 230-291.

170 M. DelCOURT, op. cit. (n. 145), p. 109.

171 Ibid., p. 97.

172 Ibid., p. 81, 93 (cratère de Bologne); 92, 107-109 (amphore panathénaïque d'Oxford).

173 Ibid., p. 107-108.

174 Héra Téleia : SÉCHAN-LÉvÊQUe, op. cit. (n. 145), p. 182, 185. 
Cette même compétence, également nuancée d'un caractère funéraire que symbolise entre autres le "collier» dont elle tire son nom ${ }^{175}$, est, dans la montagne caucasienne, celle de Samdzimari, qui partage avec Saint Georges le sanctuaire de Xaxmat'i, célèbre non seulement dans tout le pays pshav-xevsur, mais également dans toute la Géorgie orientale ${ }^{176}$. "Il se distingue de tous les autres par sa spécialisation matrimoniale, dont l'action s'exerce sur toute l'étendue de la montagne géorgienne" 177 .

Samdzimari est la démone capturée comme prisonnière de guerre ${ }^{178}$ chez les Kadzhis par Giorgi, qu'il a introduite dans son sanctuaire et qui s'est trouvée promue au rang de divinité ${ }^{179}$.

Cette étonnante métamorphose - mais après les propos de Cléombrote, elle ne nous surprend pas - reste illustrée par un rituel de Xaxmat'i auquel doivent sacrifier toutes les femmes, près du torrent Biso ${ }^{180}$, le torrent où était revenu Giorgi avec tout son butin, y allumant une grande flamme ${ }^{181}$. Le cours d'eau sépare la terre tribale et sacrée, celle du clan et du sanctuaire, du domaine hostile, dangereux et sauvage ${ }^{182}$. Massées de ce mauvais côté ${ }^{183}$ les femmes sautent l'une après l'autre par dessus l'eau pour se retrouver sur la rive droite devant un édifice dit «Tour de purification»: le nom, Sasanatlave, devrait se traduire littéralement par «baptistère» ${ }^{184}$ mais le mot ne convient pas : il n'y a pas de baptême des démons ${ }^{185}$.

Le prêtres et les servants se tiennent entre la tour et le Biso avec les victimes dont chacune a été offerte par une femme. Elle reçoit à genoux le sang de la bête égorgée avec lenteur et, prenant le jet au creux de ses

175 G. ChARACHIDZÉ, op. cit. (n. 4), p. 562 sq., 615.

176 Ibid. , p. 495.

177 Ibid., p. 626.

178 Ibid., p. 521.

179 Ibid., p. 546, 622.

180 Ibid., p. 495, 623.

181 Ibid., p. 516, 625.

182 Ibid., p. 623.

183 Ibid., p. 624, fig. 14.

184 Ibid., p. 497.

185 Ibid., p. 546. 
mains, s'en enduit la poitrine, les épaules et le visage ${ }^{186}$. C'est ce franchissement par saut du torrent et cette purification par le sang qui permettent dans le rituel et ont permis à Samdzimari «l'introduction d'un être féminin impur dans le domaine sacré»187.

On se tromperait cependant à parler de baptême et plus encore de conversion car - et c'est sans doute un reste de la prépondérance jadis exercée au Caucase par l'Iran mazdéen ${ }^{188}$, les démons restent les démons et les $X a t^{\prime} i$, les $X a t^{\prime} i$, dans un irréductible dualisme tout à fait étranger au monde hellénique. Samdzimari, forme dialectale xevsur de Samdzivari, la déesse au "collier» ${ }^{189}$, est toujours la démone vagabonde, essence même de la féminité dans ce qu'elle a de plus impur, les relations sexuelles interdites ${ }^{190}$. Elle a gardé, malgré sa promotion à l'état de divinité, les marques de sa nature démoniaque qui continue de s'exprimer par des métamorphoses et une conduite souvent impie. Déesse des femmes et du mariage ${ }^{191}$, elle exprime par là tout à la fois la nécessité de celui-ci ${ }^{192}$ et l'impureté fondamentale prêtée à celles-là par la société masculine : la femme, venue de l'étranger et de la nature sauvage, apporte avec elle sa sauvagerie en même temps que sa fécondité indispensable à l'avenir du lignage agnatique ${ }^{193}$.

Samdzimari résume cette vision dans sa double qualité d'épouse et de sœur jurée, car ses relations avec Giorgi "sont conçues comme incestueuses». Saint Georges, qui est lui-même un libertin notoire, a fait d'elle sa "sœur par serment", dobili. C'est même sous ce nom qu'elle est le plus souvent mentionnée par les Xevsur ou les tribus voisines ${ }^{194}$, et le culte personnel dont elle est l'objet tient précisément à ce statut de "sœur d'un $X a t$ 'i", créature surnaturelle intermédiaire entre les $X a t^{\prime} i$ et les démons ${ }^{195}$.

186 Ibid., p. 623-624.

187 Ibid. , p. 625.

188 Ibid., p. 705.

189 Ibid., p. 561-565 (comp. avec Cantique des cantiques, IV, 9).

190 Ibid. , p. 568, 622, 627.

191 Ibid. , p. 557, 630.

192 Ibid., p. 573.

193 Ibid., p. 631 .

194 Ibid., p. 625 .

195 Ibid., p. 142. 
Malgré la prohibition de l'inceste qui impose une stricte exogamie des unions conjugales en même temps qu'elle frappe tout rapport sexuel entre frère et sceur véritables ${ }^{196}$, l'antique modèle de l'union du frère avec sa sœur, reconstituant l'androgynie ${ }^{197}$, fait prédominer dans celle de Giorgi et de Samdzimari le rapport de c'ac'al sur celui d'époux. La contradiction s'est douloureusement inscrite dans la rélatité historique de leurs représentants royaux : le roi Georges IV surnommé Lasha et la reine Tamar, au XIIIe siècle, sont considérés par les Pshav à la fois comme époux et comme frère et sœur - alors qu'ils étaient en fait dans le rapport de fils à mère ${ }^{198}$ - et les chroniqueurs ne cachent pas leur réprobation de la conduite du roi, qui vécut maritalement avec une jeune Géorgienne, laquelle, pour comble, lui donna un fils alors que toute naissance rend les c'ac'al incestueux. Il était impensable qu'à cette époque un souverain choisît son épouse à l'intérieur de son royaume; il fallait non seulement que la future reine n'eût aucun lien de parenté avec le clan royal, mais encore qu'elle fût issue d'une lignée étrangère à la Géorgie ${ }^{199}$.

On peut dire que les rapports de Giorgi et de Samdzimari sont l'expression même de l'unité dans la dualité. Époux, ils agissent indépendamment, lui s'occupant des hommes, elle, des femmes, comme il convient à la rigoureuse séparation des sexes qui est le propre de toutes les sociétés archaïques et éclate encore aux yeux dans celles des Pshav et des Xevsur. Pseudo-frère et sœur, il ne font qu'un. Revenant à son torrent après ses multiples équipées, Samdzimari déclare : «je me lierai étroitement à mon frère juré»; le verbe employé : kindzva à l'infinitif se commente "attacher l'un à l'autre» 200 . Leur comportement para-incestueux équivaut à l'androgynie.

Que, de ces deux rapports, le plus fort soit bien le second, il existe peut-être une preuve historique qu'il l'était assez pour éclipser totalement le rapport conjugal. La plus ancienne chronique géorgienne prête à Saint André une première tentative d'évangélisation du royaume. Il s'arrête dans le sud de la Colchide en un lieu où gouvernait une femme veuve nommée Sandzivari qui se convertit et où se trouvait un
196 Ibid., p. 101-102.
197 Cf. Kernos, 6 (1993), p. 173 sq.
198 G. ChaRACHIDZÉ, op. cit. (n. 4), p. 640, 692.
199 Ibid. , p. 693-696.
200 Ibid. p. 572. 
sanctuaire païen d'Art'emi et d'Ap'olon. Grecs et Romains étaient passés par là, mais il est vraisemblable, comme le suggère Charachidzé ${ }^{201}$, que l'interpretatio graeca s'est exercée sur un couple de divinités de la Géorgie archaïque correspondant au couple fraternel Apollon-Artémis. «Si cela était et que l'on cherchât une dyade comparable dans le paganisme moderne, aucune ne conviendrait mieux que celle formée par Saint Georges et Samdzimari. Ils sont eux aussi frère et sœur, ou du moins $d z m o b i l i$ et dobili». Mais, bien entendu, il n'y a jamais eu le moindre rapport conjugal entre Artémis et Apollon.

Il est évident que rien dans Samdzimari, démone peu évoluée, ne rappelle la haute et pure image de l'Héra argienne, quoique la suspicion dans laquelle les anciens Grecs ont tenu le mariage et les femmes soit de même inspiration que la rude misogynie caucasienne.

Il n'en va pas de même pour Apollon. Archer et berger, devin, médecin, éternel voyageur devenu colonisateur (archégète) ${ }^{202}$, il est parti de ces compétences que partage K'op'ala pour développer une figure unique et admirable de divinité, dégagée de toute démonologie comme on pouvait l'attendre du génie hellénique absolument réfractaire à l'animalité fantastique des diableries. C'est d'un passé qui leur était commun qu'Apollon, dieu de la possession des âmes par l'«enthousiasme", s'est inspiré pour son carmen autant poétique que prophétique ${ }^{203}$ et pour se faire l'incomparable «maitre du chant musical et de la poésie» 204 , au point que l'art lyrique tire son nom de l'un de ses instruments de musique favoris ( $\lambda \dot{v} \rho \alpha)$.

La situation douloureuse des c'ac'al, qui, dès le début de leurs amours, savent qu'elles sont tragiquement vouées à la rupture puisque le mariage avec un autre les attend tous deux, a également donné naissance à la triste et captivante poésie caucasienne du c'ac'loba. "Tu es, dit l'un de ces montagnards à sa "sœur", tour bâtie en granit, tu m'as rassasié en vivant près de moi..., tu es source d'immortalité...". Et un autre : «La horde des loups m'assaillera, me traînera sur la rive, même alors... ma pensée sera à toi» 205 . On reconnaît là la source universelle

201 Ibid. , p. 560-561.

202 Pierre LÉVÊQUE, L'aventure grecque, Paris, 1964, p. 198.

203 SÉCHAN-LÉVÊQUE, op. cit. (n. 26), p. 208.

204 Ibid., p. 209.

205 G. CHARACHIDZE, op. cit. (n. 4), p. 99-102. 
de la poésie dite de l'«inceste littéraire» 206 , entraînant avec lui d'autres amours maudits.

Mais la source de la poésie apollinienne n'a rien à faire avec lui. Tout au contraire, on doit considérer le dieu, qui frappe Laios méprisant son oracle de l'épouvantable malheur d'un fils parricide et incestueux ${ }^{207}$, comme un héraut de la prohibition, au même titre que la déesse du mariage, Héra. Il semble même qu'on peut rattacher ce tournant historique directement à la radicale victoire de l'agnatisme grec, dont il est un des plus agressifs représentants. Aux côtés d'Athéna, qui, plus vraiment qu'Héphaistos, peut dire qu'elle n'a pas de mère, c'est lui qui affirme: «Ce n'est pas la mère qui enfante celui qu'on nomme son enfant; elle n'est que la nourrice du germe en elle semé» 208 .

"Prophète de Zeus", et parallèlement à lui, Apollon a assuré l'hégémonie masculine uaux dépens de Terres-Mères ou de jeunes dieux adolescents» 209 méditerranéens dont les rapports de fils à génitrice sont soupçonnés d'inceste. Il détrône vers l'an mil des divinités féminines qui régnaient à Délos, dont il fait son île 210 : sa sœur Artémis n'y aura plus un hieron qu'à l'intérieur du sien ${ }^{211}$. De même à Delphes, où c'est vers la fin du IIe millénaire qu'il se substitue à la déesse Terre (Gè ou Gaia) en immolant le dragon Python : les statuettes féminines si nombreuses depuis le XIVe siècle y sont remplacées par des statuettes masculines à l'époque géométrique (900-750 av. J.C.), quand commencent d'apparaître des temples ${ }^{212}$.

Est spécifiquement grecque par rapport à l'agnatisme brutal de K'op'ala-Giorgi la mesure qu'Apollon y apporte. "Particulièrement sous son aspect delphique, ce dieu nous apparaît comme l'expression la plus haute du génie grec dans le domaine religieux et moral. Sa doctrine se trouvait résumée dans les sept maximes que l'on attribuait aux Sept Sages, le chiffre sept étant essentiellement apollinien», notamment

206 Cf. Kernos, 6 (1993), p. 161, n. 118.

207 Cf. la notice de Paul Mazon, p. 103, dans son édition d'EsChyle, Les Sept contre Thèbes, aux Belles Lettres.

208 EsCHYLe, Euménides, 657 sq. (trad. P. Mazon).

209 P. LÉVÊQUE, op. cit. (n. 202), p. 95-96, 109.

210 Ibid. , p. 101, 108.

211 Ibid., p. 109.

212 Ibid., p. 157, 231. 
«Rien de trop» $(M \eta \delta \grave{\varepsilon} v$ ö $\gamma \alpha v)$, qui recommandait «de prendre conscience de toute la distance qu'il y a entre la nature humaine et la nature divine, de ne montrer d'orgueil ni envers les dieux ni envers les hommes, et de garder en tout la mesure qui préserve de l'ú $\beta \rho \imath \varsigma$ (démesure)»213. Sans doute lui fut-elle dictée par sa propre expérience, car son fol orgueil - $\alpha \tau \dot{\alpha} \sigma \theta \alpha \lambda$ os le qualifie l'Hymne homérique - fut plus d'une fois brisé par Zeus, à qui il n'avait pas toujours été soumis ${ }^{214}$.

À l'instar du couple Giorgi-Samdzimari ${ }^{215}$, le couple formé par Apollon et sa sœur Artémis se répartissait la tâche de patronage des humains par sexe. Tandis qu'Artémis s'occupait - et avec quelles exigences de chasteté ! - des femmes, Apollon exerçait son action bénéfique de façon générale sur les hommes ${ }^{216}$. Sa masculinité s'exprime dans l'obélisque ou pilier qui le figure sous l'épiclèse

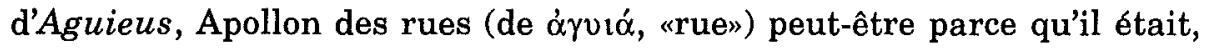

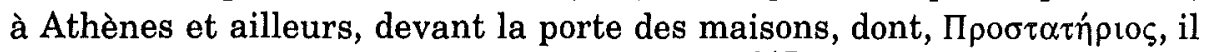
gardait "le seuil de toute influence néfaste» 217 . Nous pensons y reconnaître la valeur apotropaïque du sexe mâle en érection donneur et mainteneur de la vie, sans doute celui de l'Ancêtre ou des ancêtres (Apollo Patrôos). Il a, d'ailleurs, été souvent pris pour un hermès 218 . Jane Harrison le qualifie «Seigneur de vie» ${ }^{219}$, Pur et Purificateur, donnant la santé parce que donnant la vie, à l'instar de ce qu'elle appelle les Eniautos-daimones ${ }^{220}$. Apollon Aguieus, dit-elle encore ${ }^{221}$, est essentiellement un Agathos Daimon.

La Souda et d'autres sources voient dans cette représentation d'Apollon en cône effilé un motif dorien. De fait, toutes les monnaies où

213 SÉCHAN-LÉVÊQUE, op. cit. (n. 26), p. 213.

214 Ibid., p. 203-204.

215 Giorgi et Samdzimari sont les protecteurs respectifs de la société masculine et de la fécondité (G. Charachidzé, op. cit. (n. 4), p. 633), la composante féminine de la société demeurant tout à fait étrangère à Girogi, dieu des hommes et de la continuité du lignage (ibid., p. 490).

216 SÉCHAN-LÉVÊQUE, op. cit. (n. 26), p. 206 et 220 , n. 86.

217 Ibid. , p. 206.

218 J.E. HARRISON, Themis, Cambridge, 1912, p. 410.

219 Ibid. , p. 424, 439.

220 Ibid. , p. 437 et n. 1.

221 Ibid., p. 409, n. 4. 
il est figuré sont des monnaies de colonies doriennes ${ }^{222}$. Elle en décrit certaines avec précision : celles de Mégare, de Byzance, une colonie dorienne, d'Apollonie en Illyrie, d'Ambracie en Épire ${ }^{223}$, à quoi il faut ajouter une précieuse représentation d'un vase de la Villa Albani ${ }^{224}$.

$\mathrm{Au}$ sommet du cône se trouve une couronne, et aussi, à mi-hauteur, des patères dont certaines portent encore une couronne votive. La couronne répond à celle par laquelle Apollon avait consacré sa purification et celles qu'après lui, les jeunes couroi delphiens ses émules allaient se faire à Tempé $e^{225}$. Mais en outre, un filet s'enroule autour du cône aux deux tiers de sa hauteur (Villa Albani, Mégare) ou bien (Ambracie) deux filets partent de sa pointe.

On pense tout de suite à l'apex, pointe, sommet du bonnet des flamines, qui était constitué par une petite baguette entourée de laine, «langue de flamme», «aigrette» fermant ainsi le bonnet et attachée de chaque côté par un bandeau; le mot apex pourrait venir de l'étrusque ${ }^{226}$. La laine, en tout cas, est le symbole même de l'épouse et l'on sait que la flaminica était indispensable au ministère de son mari ${ }^{227}$.

Mieux encore : ce filet évoque directement celui qui, à Delphes, enveloppait l'omphalos. Sans revenir sur toutes les interprétations qui ont été données, et cela dès l'antiquité même, de cet omphalos et dont chacune doit contenir une part de vérité, tenons-nous en à sa qualification régulière par les textes anciens de "nombril de la terre", ó $\mu \varphi \alpha \lambda \grave{o} s$ $\gamma \eta \hat{\zeta}$, omphalos étant l'équivalent du latin umbo, la ubosse" au centre du bouclier protecteur ou celle que le nombril fait au milieu du ventre.

Les philosophes et les médecins grecs appelaient l'omphalos une racine $^{228}$ : le cordon ombilical est une racine qui attache l'enfant à sa mère et, commencement de tout pour lui, comme s'il ne devait jamais se détacher d'elle, elle symbolise la protection que, pour le restant de sa vie, cette mère continuera de lui assurer, une protection si importante que, dans les anciens royaumes interlacustres d'Afrique noire, quand la

222 Ibid. , p. 408-409.

223 Ibid. , p. 406, fig. 118 et 119.

224 Ibid., p. 407, fig. 120.

225 Cf. supra, p. 231.

226 ERnOUT-MeILlet, Dict. étymol. et A. RICH, Dict. des Ant., s.v.

227 BouCHÉ-LECLERCQ, Manuel des institutions romaines, Paris, 1931, p. 514, n. 7.

228 M. DELCOURT, op. cit. (n. 30), p. 145. 
mère du roi venait à mourir, on s'empressait de lui donner une mère substitutive, magiquement indispensable à sa propre survie.

L'omphalos de Delphes était l'omphalos de la Terre, dont nous savons qu'elle fut la première détentrice de l'oracle. Justement, «l'omphalos appartient probablement à la couche préhellénique des cultes de Delphes et, dès l'époque la plus haute à laquelle nous puissions atteindre, il a cessé d'avoir pour les Grecs une significätion unique» 229 . Vraisemblablement, il correspond à un temps où la naissance d'enfants était attribuée, sinon exclusivement, du moins principalement à la femme.

Il reste à expliquer la présence du filet le recouvrant d'une façon qui pourrait et devrait rendre compte aussi du filet de l'Aguieus. Pausanias avait vu l'un des deux exemplaires de l'omphalos, celui qui était à l'extérieur, à l'entrée du temple, sous un palmier, rappel sans doute du célèbre palmier de l'accouchement de Léto à Délos. Il le décrit ${ }^{230}$ comme fait de marbre (calcaire ?) blanc avec le filet sculpté dans la pierre. C'est celui qu'ont mis au jour les fouilles françaises ${ }^{231}$, auquel Jane Harison consacra un article intitulé AEgis-Agrènon, «Égide et Filet» 232 , justement relatif à cette décoration : elle donnait judicieusement en effet à l'agrènon une valeur autonome, identifié qu'il est par des notes de lexicographes avec l'égide et le filet tressé dont sont revêtus les devins 233 .

En fait, l'agrèmon n'est pas en lui-même une garde ni un vếtement: c'est un filet, destiné, comme l'indique l'étymologie d'agrènon qui vient des verbes $\dot{\alpha} \gamma \rho \varepsilon v ́ \omega, \dot{\alpha} \gamma \rho \varepsilon ́ \omega$, à capturer le gibier, à la chasse ou à la pêche de telle façon que, sans être tué, il soit retenu. L'agrènon emprisonne donc l'omphalos, c'est-à-dire le cordon ombilical par lequel la mère donne nourriture, naissance, vie après qu'elle a satisfait son désir de l'homme. Il ne s'agit certes pas de limiter le nombre des naissances, et la fécondité de la femme reste le but à atteindre, mais son sexe, pour stimulé qu'il doive être, est à défendre, non seulement contre les agressions masculines, mais contre lui-même: ses désirs doivent être contenus, retenus.

$230 \mathrm{X}, 16,3-4$.

231 Reproduit dans le Themis de J.E. HARRISON, p. 398, fig. 110.

$232 B C H, 24$ (1900), p. 254. Cf. Themis, p. 398 et n. 1.

233 M. DelcourT, op. cit. (n. 30), p. 147. 
Ion, dans la tragédie d'Euripide, mentionne l'omphalos comme "couvert de bandelettes, accosté de Gorgones» 234 . Strabon parle, non de filet, mais de réseau de bandelettes. Les liens portés par les statuettes d'Héra samienne «ressemblent aux bandes d'un maillot qui se croiseraient exactement sur le sexe» ${ }^{235}$ et «les initiés de Thrace portaient des bandelettes rouges fixées sur le bas-ventre, c'est-à-dire, semble-t-il, croisés sur le sexe» 236 . On ne sait trop comment imaginer les têtes de Gorgones autour de l'omphalos ${ }^{237}$. R. Flacelière ${ }^{238}$ estime que le bétyle était entouré d'un réseau de bandelettes ou de filets de laine et que les têtes de Gorgone étaient à l'intersection des mailles du réseau.

De façon ou d'autre, le propre des têtes de Gorgone était de pétrifier qui les regardait, et la pétrification équivaut à l'immobilisation par des liens, bandelettes, bandeau ou un filet : c'est ce qui arriva à Thésée et Pirithoüs qui étaient descendus aux Enfers dans l'intention d'enlever Perséphone. Hadès les fit courtoisement asseoir sur un rocher où leur peau se colla, «ce qui vaut bien des chaînes». Ils étaient cependant restés vivants puisque Héraclès parvint à arracher Thésée qu'il ramena au jour, mais il dut abondonner Pirithoüs car sa tentative provoqua un tremblement de terre ${ }^{239}$.

Bien entendu, les têtes de Gorgone, menaçantes, étaient d'abord destinées à décourager les agressions de l'extérieur, venues de mâles mortels ou Immortels. Méduse avait été violée par Poséidon à l'intérieur d'un temple d'Athéna et elle était tombée enceinte : Athéna orna donc son bouclier de la tête de Méduse tranchée par Persée. Mais les vierges devaient être également protégées contre elles-mêmes; Athéna et plus encore Artémis y veillaient farouchement.

L'omphalos, symbole de la maternité, est bien encouragement à la fécondité des femmes et, par là, à la sexualité féminine, mais seulement en mariage. Sans doute parait-il surprenant qu'un tel but se voie

234 Ion, 224.

235 M. DELCOURT, op. cit. (n. 145), p. 101.

236 Ibid., p. 102.

237 Cf. la note 2, p. 192, de Parmentier-Grégoire dans leur édition de l'Ion aux Belles Lettres.

238 Le fonctionnement de l'oracle de Delphes au temps de Plutarque, in Annales de l'École des Hautes Études de Gand, II, Études d'archéologie grecque, Gand, 1938, p. 84.

239 M. DelCOURT, op. cit. (n. 145), p. 98. 
opposer un obstacle, le filet, mis à son accession. Mais c'est tout le problème de la fécondité liée à la chasteté ${ }^{40}$. À propos d'Apollon, justement, liant Hermès avec des rameaux de gattilier que son jeune frère multiplie instantanément ${ }^{241}$, elle mériterait d'être approfondie cette remarque : «que féconder trouve son équivalent en "lier une femme", tandis qu'accoucher se rattache au verbe signifiant "délier" suppose que, dans les pratiques qui entourent la grossesse et l'accouchement, le lien joue continûment un rôle important» 242 .

Tout changea à Delphes lorsqu'Apollon affirma avec Zeus la prépondérance masculine dans la filiation. L'omphalos-racine, éminemment chthonien, se prêta naturellement à devenir le centre de la terre déterminé par la rencontre de deux aigles de Zeus venant d'horizons opposés. Tempérer ses ardeurs devait être plus que jamais rappelé au sexe masculin, et c'est à quoi répond la diffusion de l'image symbolique d'un ithyphalle au filet qui est celle d'Apollon Aguieus. La modération doit être la règle et dans le comportement sexuel en mariage et dans le traitement de la femme. Elle inspire l'institution de mariage lui-même.

Le mariage, voilà le filet. L'équilibre dans la société comme dans l'univers est au prix d'une fécondité ordonnée et d'une sexualité contrôlée (Dumézil). Nous retrouvons là l'opposition heureusement décrite par M. Detienne entre la sexualité sage du mariage générateur de postérité et la débauche stérile qui s'incarne en la personne fatale d'Adonis 243 .

Donc Apollon avait pris possession de l'oracle de Delphes en succédant à Gaia et éliminant son «fils» et gardien Python, qui ne reçut d'honneurs funèbres que de la part de "La Chèvre" (Aix), un animal monstrueux pour les Grecs, impur et créature du démon pour les montagnards caucasiens ${ }^{244}$. Mais ce transfert de souveraineté ne faisait que s'inscrire dans une révolution sociologique profonde et décisive dont il

240 L'omphalos de Delphes a passé pour le siège de la vierge Hestia et l'est même resté dans un langage liturgique (P. Roussel, Hestia à l'omphalos, in $R A$ [1911], p. 86 sq.).

241 Laurence KAHN, Hermès passe ou les ambiguïtés de la communication, Paris, 1978, p. 113.

242 Ibid., p. 103.

243 Les Jardins d'Adonis, Paris, 1972, p. 157, 230-232 et passim.

244 G. CharaChIDZE, op. cit. (n. 4), p. 279, 706. 
ne constitue que la partie émergée de l'iceberg ${ }^{245}$. Cléombrote paraît en être conscient quand, ayant rappelé la suite des phases du Septérion, «tout cela, constatait-il ${ }^{246}$, fait soupçonner qu'il s'agit de quelque grand et audacieux sacrilège».

Apollon ne faisait que profiter du triomphe de l'agnatisme, analogue à celui que consacrait Giorgi en transformant, à son retour de Kadzhéti, une fille en garçon pour assurer la pérennité d'une lignée masculine. Or cela cache des changements d'une extrême importance, des inversions radicales de ce que l'on est habitué à connaître, qui frappent d'une surprise émerveillée, que seul peut accueillir un grand silence, qui provoquent le sentiment de quelque chose d'inexplicable, proprement de magique : la magie, c'est le "pied retourné», talon en avant, la "main à l'envers» pour accomplir un sacrifice, comme celui d'une chèvre aux démons 247 .

Qu'on songe aux réactions du premier homme devant le premier feu ! L'attitude prise alors se perpétue devant celui qu'on allume dans une nouvelle maison. G. Charachidzé insiste sur cette "grande affaire», qui "inaugure une période neuve" et a cherché à cerner le rôle qu'y tient Giorgi ${ }^{248}$. Ce rôle concerne la rupture avec le passé, avec le chemin jusque-là parcouru et le «changement d'état qui en résulte». C'est la même incertitude qui déclenche les pratiques et coutumes du Nouvel An.

Un inextricable mélange de fête chrétienne et de traditions païennes continue aujourd'hui encore au Caucase à célébrer ce complet bouleversement annuel. La chasse donnée aux démons pendant la semaine sainte ou "semaine des démons» exprime le vœu d'en finir avec l'année écoulée, dont la détérioration risque d'entraîner le bouleversement de l'ordre des choses. «La machine du temps s'est usée au cours des douze mois précédents... les dispositifs assurant normalement l'ordre du monde et l'organisation de ses composantes ne fonctionnent plus... les démons régnant sur les espaces sauvages et qui s'y trouvent confinés

245 Cf. Kernos, 6 (1993), p. 143-144, comp. p. 153-156.

246 L'irruption silencieuse des Æolades et de l'amphithalès à la lueur des torches, la mise à feu de la "cabane», le renversement de la table, leur fuite sans retourner la tête, la course errante enfin de l'enfant, sa servitude et ses purifications à Tempé, De def. oracul., 418a-b (15).

247 G. CHARACHIDZÉ, op. cit. (n. 4), p. 653, 654, 664, 697.

248 Ibid., p. 487 sq. 
ont mis à profit l'écoulement du temps pour se rapprocher...» 249 . "Le jeudi saint marque la victoire finale sur les démons, acquise jusqu'à l'année suivante...»250.

Dans la Grèce ancienne, c'était chaque année au printemps que se faisait le passage des pouvoirs entre le vieil «Eniautos-daimon» $251 \mathrm{de}$ l'année expirante et sa renaissance ou résurrection en jeune et nouvel "Eniautos-daimon» ${ }^{252}$. C'était la fête de l'An ('Evı $\alpha$ ¿ós, "l'anneau») Nouveau.

À Delphes, il avait fallu beaucoup de temps à Apollon pour revenir après y avoir rompu avec le passé : neuf années, et même, suivant Cléombrote ${ }^{253}$, neuf "grandes années", c'est-à-dire neuf fois "une période cosmique au terme de laquelle l'univers se trouve entièrement renouvelé» 254 . Une si exceptionnelle durée magnifiait l'avènement d'un dieu.

Avenue du Prado, 441

Jacques-Numa LAMBERT

Résidence Victoire

F - 13008 MARSEILLE

249 G. CHARACHIDZÉ, op. cit. (n. 18), p. 111.

250 Ibid., p. 113.

251 Jane Harrison reconnaît que l'expression ne se trouve pas chez les Grecs qui préfêrent parler, par exemple, comme en Béotie, d'Agathos Daimon (Themis, p. 327, n. 2).

252 Ibid., p. 155-156, 225, 323, 427, 429.

253 De def. oracul., 421c (21).

254 R. FLACELIÈE, Dialogues pythiques, op. cit. (n. 1), p. 126, n.4 (p. 189). 


\section{TABLE DES MATIÈRES}

\section{Chapitre III : Les démons et Apollon}

Cléombrote s'explique sur les démons, aptes à la divination et intermédiaires entre les dieux et les hommes, mais qui peuvent se hausser au niveau divin après une purification qui évoque celle des neuf années passées par Apollon "dans un autre monde». Le paganisme caucasien porte à son sommet une sorte de seigneur des démons, l'Ange (Xat'i) $K^{\prime}$ op'ala, dont le nom assonnant avec celui d'Apollon n'est pas le seul indice de leur cousinage, 231-233. - K'op'ala, libérateur des âmes que les démons retiennent captives, sauvé lui-même du lac Abelaur (Avallon?) où il avait plongé à leur poursuite, remonte au ciel et retrouve son sanctuaire, 233-235. - Analogies entre $K^{\prime}{ }^{\prime} p^{\prime}$ ala et l'Apollon-Loup de Delphes, 235-237. - Inceste et mariage dans la fête du Steptérion et dans le contexte caucasien de la légende de K'op'ala, 237240. - Analogies entre Apollon et Giorgi (saint Georges), plus ou moins identifié à $K^{\prime} o p^{\prime} a l a, 241-242$. - Le silence et le bruit aux effets à la fois cosmologiques et sociologiques en Europe ainsi que chez les Indiens d'Amérique du Sud, 242-246. - À Sumer déjà, 246-248. - Orgueilleux, vains et sacrilèges défis pour rapprocher la Terre du Ciel, 248-255. - Les liens, nécessaires au maintien de l'ordre du monde et de la chasteté : passage d'un état d'impureté à la fonction de déesse du mariage pour Héra chez les Grecs, 255-258. - De même chez les Caucasiens pour Samdzimari, "sœur jurée" et épouse de Giorgi comme Héra est la sœur et l'épouse de Zeus : c'est la confirmation que l'archétype du mariage fut l'union d'un frère et d'une sœur, 259-262. - Apollon héraut de l'agnatisme prohibe aussi l'inceste, 262-264. - Apollon Aguieus et le filet de l'omphalos de Delphes, dont le sens est celui-là même des liens, 264-268. - La prise de possession de Delphes par Apollon est sociologiquement la fin d'une époque et le commencement d'un âge nouveau, 268-270. 